\title{
Decreasing stand density favors resistance, resilience, and recovery of Quercus petraea trees to a severe drought, particularly on dry sites
}

\author{
Anna Schmitt ${ }^{1,2} \cdot$ Raphaël Trouvé $^{3} \cdot$ Ingrid Seynave $^{1} \cdot$ François Lebourgeois $^{1}$
}

Received: 20 December 2019 / Accepted: 28 April 2020 / Published online: 26 May 2020

(C) INRAE and Springer-Verlag France SAS, part of Springer Nature 2020

\begin{abstract}
- Key message Decreasing stand density increases resistance, resilience, and recovery of Quercus petraea trees to severe drought (2003), particularly on dry sites, and the effect was independent of tree social status.

- Context Controlling competition is an advocated strategy to modulate the response of trees to predicted changes in climate.

- Aims We investigated the effects of stand density (low, medium, high; relative density index 0.20, 0.53, 1.04), social status (dominant, codominant, suppressed), and water balance (dry, mesic, wet; summer water balance $-182,-126,-96 \mathrm{~mm}$ ) on the climate-growth relationships (1997-2012) and resistance (Rt), resilience (Rs), and recovery (Rc) following the 2003 drought.

- Methods Basal area increments were collected by coring (269 trees) in young stands (28 \pm 7.5 years in 2012) of sessile oak (Quercus petraea) in a French permanent network of silvicultural plots.

- Results We showed that the climate-growth relationships depend on average site-level water balance with trees highly dependent on spring and summer droughts on dry and mesic sites and not at all on wet sites. Neither stand density nor social status modulated mean response to climate. Decreasing stand density increased Rt, Rs, and Rc particularly on dry sites. The effect was independent of tree social position within the stand.
\end{abstract}

- Conclusion Reducing stand density mitigates more the effect of extreme drought events on drier sites than on wet sites.

Keywords Resistance $\cdot$ Resilience $\cdot$ Drought $\cdot$ Stand density $\cdot$ Quercus petraea $\cdot$ Silvicultural network

Handling Editor: Marco Ferretti

François Lebourgeois

francois.lebourgeois@agroparistech.fr

Anna Schmitt

anna.schmitt@onf.fr

Raphaël Trouvé

raphael.trouve@unimelb.edu.au

Ingrid Seynave

ingrid.seynave@inra.fr

1 Université de Lorraine, AgroParisTech, INRAE, Silva, 54000 Nancy, France

2 Office National des Forêts, Unité Territoriale de Vesoul, 70000 Vesoul, France

3 Department of Forest and Ecosystem Science, University of Melbourne, Richmond, VIC 3121, Australia

\section{Introduction}

In the next decades, climate warming is expected to increase leading to more frequent heatwave and drought events (Jentsch and Beierkuhnlein 2008; Schar et al. 2004; Sterl et al. 2008). As in forest stand, soil water is one of the main resource that trees must share (Granier et al. 1999); progressive or abrupt changes in soil constraints can trigger important tree dysfunctions (Allen et al. 2010; Gustafson and Sturtevant 2013; Neumann et al. 2017) and play a major role in shaping forest ecosystems (Ruiz-Benito et al. 2017).

For tree species, radial growth is commonly used as an indicator of vigor (Cailleret et al. 2016) and tree-ring analyses allow quantifying the impact of direct or delayed climate events on trees (Bréda et al. 2006; Gutschick and BassiriRad 2003). The tree response to a stressful event can be analyzed through different indices highlighting the direct and lag effects of the disturbance: resistance (Rt), recovery $(\mathrm{Rc})$, and resilience (Rs) (Gunderson 2000; Lloret et al. 2012; Lloret et al. 2011; Pretzsch et al. 2013; Trouvé et al. 2016). In the case of 
the radial growth, Rt describes the degree to which the growth is changed during the disturbance. Rc and Rs describe the tree's ability to get its growth back and to fully recover its pre-disturbance growth level after the disturbance event.

Reports of the thinning effect on tree growth cover numerous species across wide geographical ranges (Sohn et al. 2016). In the short and medium terms (1 10 years), thinning promotes the growth of remaining trees, the increase being positively correlated with thinning intensity. The underlying ecophysiological mechanisms of the thinning effects are varied and usually complex to study. Decreasing density modifies the microclimate within the stand: light, temperature, water, and wind (Aussenac 2000). It leads to important changes in tree functioning (photosynthesis, transpiration) which modifies carbon allocation and thus growth, form, and size of the remaining trees (Trouvé et al. 2015). It is largely accepted that decreasing density increases soil water availability (Aussenac and Granier 1988; Bréda et al. 1995) at least in the medium term before the tree or understorey canopy has closed. Thus, decreasing competition may modulate treering growth-climate relationships by changing both the strength and the nature of the climatic drivers (Lebourgeois et al. 2014). Indeed, as reducing competition improves the soil water availability (Bréda et al. 1995), the amount of water shareable for the remaining trees increases leading to a decreased competition for this resource and thus a lower response to drought (Bréda et al. 2006). Consequently, lowdensity stands are expected to have lower correlations with precipitation and water balance than high-density stands. At the tree level within stands, a common hypothesis is that suppressed trees (i.e., trees with a lower relative tree size) are growing close to their lower survival threshold. They have a low ability to acquire extra resources and low growth potential (Bréda et al. 1995), decreasing their capacity to respond to water availability (weak climate response) (Lebourgeois et al. 2014). On the other hand, dominant trees (i.e., trees with a higher relative tree size) are seldom limited by light availability (Sánchez-Salgueroa et al. 2015) and have faster growth rates but may also be more vulnerable to variation in climatic conditions than suppressed individuals.

Decreasing competition within stand has been widely advocated as a strategy to cope with predicted changes in climate (D'Amato et al. 2011; Lindner et al. 2010) and to enhance Rt, Rc, and Rs to drought (Sohn et al. 2016). However, several recently published studies revealed complex interactions among many factors leading to an important variation of Rt, $\mathrm{Rc}$, and Rs with (1) the extreme drought considered, (2) the thinning intensity, (3) the time span between the thinning and the drought, and (4) the soil water holding capacity of the site. Stronger thinning improved Rt and Rs in Picea abies stands in Germany (Kohler et al. 2010; Sohn et al. 2013) and in the Belgium Ardennes (Misson et al. 2003a, b), particularly on wet sites. Opposite results have been observed in northern
Virginia broadleaved forest ecosystems (Orwig and Abrams 1997) and in French sessile oak stands (Trouvé et al. 2016), with a lower Rs on wet sites. The response to extreme events can also vary according to tree social status. Thus, some studies reported a higher Rt and Rs of dominant trees (MartinBenito et al. 2008; Pichler and Oberhuber 2007; Trouvé et al. 2016; Vose and Swank 1994), whereas others showed the opposite (Liu and Muller 1993). Similar various results have been observed with tree size (Martinez-Vilalta et al. 2012; Mérian and Lebourgeois 2011a, b; Zang et al. 2012). Concerning age, young trees appeared also more resistant and resilient to disturbance than older ones (D'Amato et al. 2013). Lastly, a close interaction between social status and site water balance has also been observed (Orwig and Abrams 1997; Trouvé et al. 2016).

Long-term silvicultural experiment networks are crucial to test and quantify the effect of stand density on tree response to disturbance and to build growth models adapted to new forestry practices (D'Amato et al. 2011; Pretzsch et al. 2019; Seynave et al. 2018; Trouvé et al. 2019). As the response to drought has been shown to vary with locally adapted ecotypes (SaenzRomero et al. 2017), the experiments should cover large spatial scales and contrasted site water balance, as determined by local climate and soil characteristics (Seynave et al. 2018).

In the present study, we explored the effects of stand density, social status, and water balance on the tree growth response of Quercus petraea Liebl. (sessile oak) stands to climate. We seek to highlight how these factors influenced both the response to climate through bootstrapped correlation analyses and the response to severe drought (i.e., 2003) through the analysis of resistance, resilience, and recovery. We based our study on sessile oak as one of the major broadleaved species in Europe (Saenz-Romero et al. 2017) and the second broadleaved tree species in France in terms of growing stock with $281 \mathrm{Mm}^{3}$. We used tree-ring data sampled in the sessile oak GIS Coop network. This network consists of young trees ( $\sim 10$ to 40 years). It covers a maximum range of relative stand density, ranging from self-thinning stands (high density) to an absence of competition among trees (low density, called open growth) and a wide range of site water balance conditions (wet, mesic, and dry sites) (Seynave et al. 2018; Trouvé et al. 2019). For the extreme event, we focused our attention on 2003 which was one of the most severe drought in Europe in recent decades (Bréda et al. 2006; Rebetez et al. 2006). For each of the 269 sampled trees, we investigated the resistance during the 2003 drought year and the recovery and resilience three years after the drought (Lloret et al. 2011; Pretzsch et al. 2013).

The present work follows the previously published study of Trouvé et al. (2016) led from data collected in even-aged sessile oak stands ( $\sim 100$ years) in another long-term experimental network. While the work of Trouvé et al. (2016) clearly showed the importance to decrease stand density to cope with extreme climatic events and the interactions with local

\section{פ2 Springer INRAC}


ecological conditions, it only covered a limited relative density gradient (RDI) (Reineke 1933) from 0.5 to 1 . However, recent thinning prescriptions suggested by foresters to cope with environmental changes cover RDI values well below 0.5 . Yet, the effect of these thinning prescriptions on drought resistance and resilience has not been thoroughly tested. There is thus a need to quantify whether growing trees at densities lower than currently practiced (RDI largely below 0.5 ) will further improve tree resistance and resilience to droughts. A better understanding of the response at an earlier development stage is also crucial to improve forest management practice and mitigate the impact of climate change on our forests. By contrast with the previous study (Trouvé et al. 2016), our present study will focus on the 2003 drought, which is one of the main recent droughts in Europe. Many authors have suggested that the exceptional summer conditions of 2003 will be considered "normal" summer conditions in future years.

Thus, to give new insights on the importance to sharply decrease stand density (RDI largely below 0.5 ) for young trees ( $<40$ years) to better cope with an extreme drought year, we performed a new analysis from the GIS Coop network. The hypotheses tested were as follows: (1) trees grown in drier sites respond differently to climate (higher sensitivity or different climatic drivers) and have lower Rt, Rc, and Rs than trees grown in moister sites, as they experience higher summer soil water deficit during the drought; (2) trees grown at greater stand density level respond differently to climate (higher sensitivity or different climatic drivers) and have a lower Rt, Rc, and Rs than trees grown at a lower-density level; (3) suppressed trees have a higher sensitivity to climate and a lower Rt, Rc, and Rs than dominant trees; and (4) the effect of a low stand density on tree response to drought increases in drier sites.

\section{Material and methods}

\subsection{Study area and experimental design}

The data originated from the long-term GIS Coop sessile oak experimental network (Seynave et al. 2018; Trouvé et al. 2019). The sites are located in the plains of Northern France (Table 1). The "Parroy" site had a semi-continental climate and defined the "wet" site of the experimental design. Grosbois and Réno-Valdieu sites had an altered oceanic climate with "mesic" conditions and the Montrichard site corresponded to a "dry" site. Wet, mesic, and dry conditions corresponded to the three water balance classes used as stratification factor (hereafter, named $\mathrm{HBc}$ ). As commonly practiced for even-aged forestry in France, stands were naturally regenerated. Each site contained from 2 to 3 experimental plots $(0.36 \mathrm{ha})$ with young trees $(28 \pm 7.5$ years in 2012$)$ that were subject to contrasted density treatments (Tables 1 and 2). Since the start of the experiment (1995 to 1997 depending on the experimental design), the stands have been thinned many times (Table 1). Stand thinning was triggered whenever the relative stand density of the plot was above the target RDI-age trajectories (Annex 1). The thinning was always done before the start of the growing season and from below: smaller than average trees were removed during thinning. The type of thinning is usually quantified by the $k$ factor, computed as the ratio between $\mathrm{dg}$ of thinned trees to $\mathrm{dg}$ before thinning (Trouvé et al. 2019). It is equal to 0.91 in our data (Annex 1).

\subsection{Climatic data and water balance modeling}

Climatic data were obtained for each site from the Safran spatial climate model (Vidal et al. 2010). We extracted precipitation $(P)$ and temperature $(T)$ data for the period 1997-2012 and thereafter, we calculated potential evapotranspiration (PET) and "climatic" water balance (HB). PET was calculated using Turc's formula (Turc 1961) and HB as an index of remaining available water once evaporation and transpiration have removed a part of it coming from precipitation $(\mathrm{HB}=\mathrm{P}-\mathrm{PET})$. We also used the modeling method developed by (Thornthwaite and Mather 1955 ) to perform a soil water balance that has been successfully used in many previous studies (Lebourgeois et al. 2013; Trouvé et al. 2016). The soil water holding capacity for each site (SWHC) was calculated thanks to the R package EUPTF (Toth et al. 2015) based on textural properties, depth, and percentages of the coarse element of each soil horizon for a depth of $100 \mathrm{~cm}$ (Bergès and Balandier 2010). The main output of the water balance modeling was the evaporation deficit $(\mathrm{ED}=$ actual evapotranspiration - potential evapotranspiration). Vapor pressure deficit (VPD) was also further calculated (Trouvé et al. 2015). As the climate was different depending on the sites, we calculated water balance anomalies to compare summer drought (cumulated values (in $\mathrm{mm}$ ) of $\mathrm{HB}$ or ED for the period June from August) over sites (Eqs. (1) and (2)).

HB anomaly $y_{\text {year } i}$

$$
=\frac{\text { observed summer } \mathrm{HB}_{\text {year } i}-\text { mean summer } \mathrm{HB}_{(1997-2012)}}{\text { summer HB standard deviation }_{(1997-2012)}}
$$

ED anomaly year $i$

$$
=\frac{\text { observed summer } \mathrm{ED}_{\text {year } i}-\text { mean summer } \mathrm{ED}_{(1997-2012)}}{\text { summer ED standard deviation }}
$$

\subsection{Stand variables and tree diameter rank}

The relative density index (RDI, dimensionless) was used as a stand density index for two main reasons. First, it was used to define and apply density treatments in the GIS Coop plots 


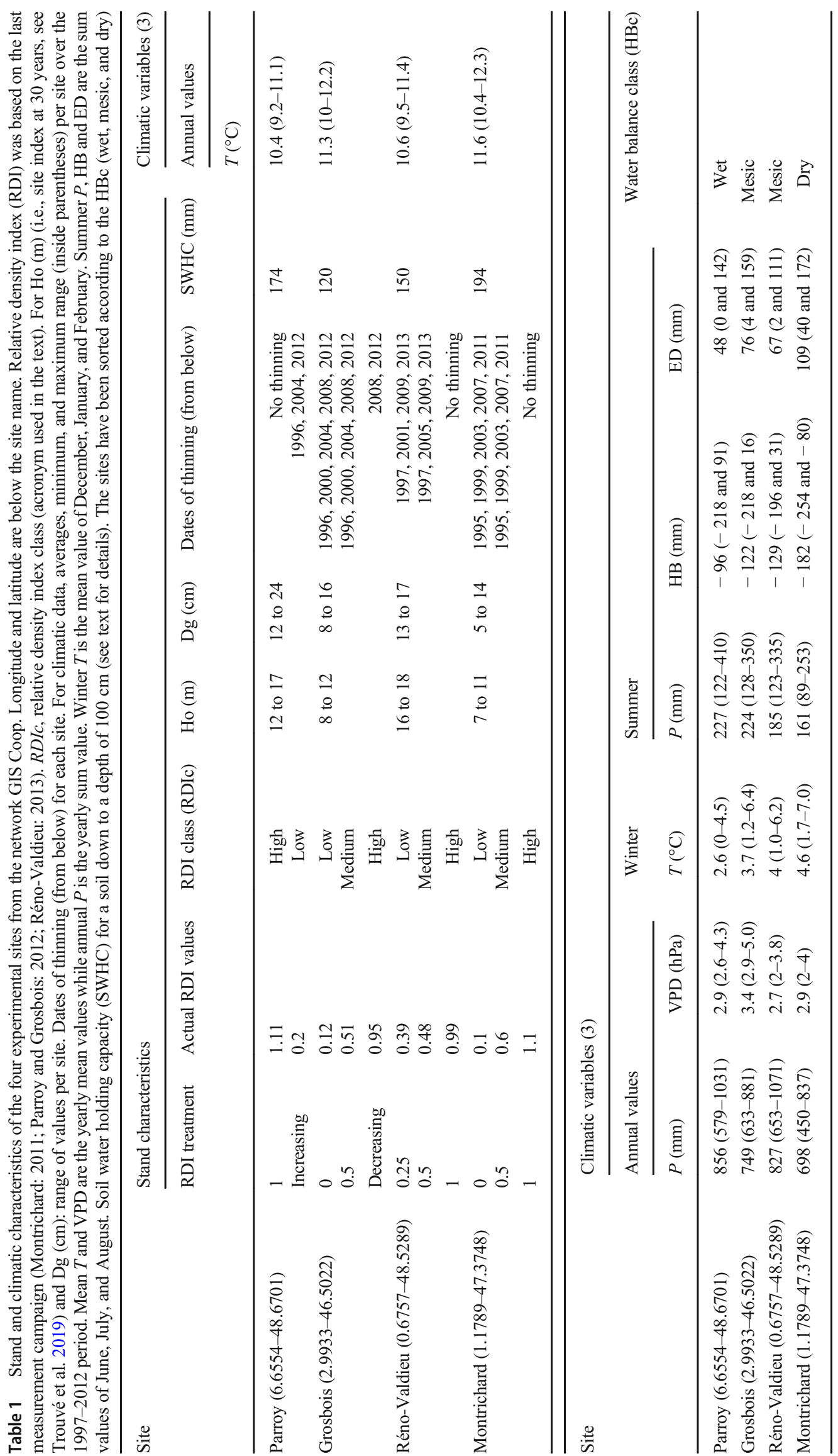


(Seynave et al. 2018; Trouvé et al. 2019). Second, this index does not depend on the stand age nor on the site fertility (Reineke 1933). RDI describes the current density ( $N$, in stems/ha) relative to the threshold self-thinning density $\left(N_{\max }\right.$, in stems/ha) at the current quadratic mean diameter ( $\mathrm{dg}$, in $\mathrm{cm}$ ) and is used to express plot density on a relative scale. RDI was calculated from (Le Goff et al. 2011) which is calibrated for sessile oak in its production area in France (Eq. (3)). The selected plots covered a range of RDI from 0 to 1.3.

$\mathrm{RDI}=\frac{N}{N_{\max }}=\frac{N \times \mathrm{dg}^{1.566}}{125.242}, \operatorname{using} N_{\max }=\frac{125.242}{\mathrm{dg}^{1.566}}$

Six different density treatments have been applied: four constant RDI over the tree lifetime (RDI $\sim 0,0.25,0.5$, and 1 ), one increasing, and one decreasing RDI treatments (Table 1) (Seynave et al. 2018). In the mesic site located in Grosbois, the phase of RDI decreasing was progressive and began only in 2008 (first thinning) and the RDI in 2012 was equal to 0.95 (Table 1 and Annex 1). In the same way, the RDI in the wet site (Parroy) subject to an increasing RDI treatment was always low (0.20) in 2012 (Table 1 and Annex 1). Decreasing and increasing RDI treatments are henceforth merged with RDI $\sim 0$ and RDI $\sim 1$ treatments, respectively. Finally, we defined three stand density classes (hereafter named RDIc) corresponding to three classes of RDI: low, medium, and high. They averaged respectively $0.20,0.53$, and 1.04 (Table 1).

We used relative tree diameter rank (dimensionless) in 2012 as a proxy for individual tree social status within each plot (Trouvé et al. 2016). For each plot, the diameter rank was computed by first ranking trees by increasing size. This raw rank was then divided by the number of trees of the plot. Diameter rank was grouped into three social status categories (hereafter SSc): trees with diameter rank below 0.3 in 2012 were considered to be suppressed trees (S), trees with diameter rank between 0.3 and 0.6 were considered to be codominant trees $(\mathrm{C})$, while trees with diameter rank above 0.6 were considered to be dominant trees (D). While this threshold avoids introducing any subjective selection bias and objectively splits the population into three (Table 2), care should be taken when interpreting the response of social status categories among different stand density treatments. Per our definition, the suppressed trees (diameter in the 0 0.3 percentile range) in the high-density stands are typically more "suppressed" than the suppressed trees in the medium- and lowdensity stands (Annex 2). For this reason, we suggest focusing not only on the effect of social status by itself but also on the combination of social status and stand density classes (i.e., the interaction term) when interpreting our results.

\subsection{Annual tree growth and master chronologies}

For each RDI treatment $(0.20,0.53$, and 1.04$)$, annual basal area increments (BAIs) were calculated from increment cores collected in 2012 (19 to 29 trees per treatment; total $=269$ trees, one core per tree) evenly distributed along the diameter distribution to represent each social status (Table 2). Ring width chronologies were recorded using the LINTAB platform. The individual series were measured at $0.01-\mathrm{mm}$ resolution and cross dated afterwards by progressively detecting regional pointer years by using the $\mathrm{R}$ software POINTER (Mérian 2012). We used the "dplR" package (Bunn 2008) to compute the tree-ring series for the maximum period common to all strata (1997-2012, 16 years) and standardized these ring series individually to emphasize the inter-annual climatic signal. We chose 1997 as the beginning of the period as RDI treatments in the GIS Coop network plots were not effective before that year. For each tree, a double-detrending process, based on an initial negative exponential or linear regression followed by fitting of a cubic smoothing spline was applied (Mérian 2012). Hereafter, a master chronology was built for one single social status (D, C, and $\mathrm{S}$ ) in a plot defined by its RDIc (low, medium, and high) and HBc (wet, mesic, dry). A total of 33 master chronologies were built in the same way (Annex 3). They were used to explore the climate-tree growth relationships over the whole period from 1997 to 2012 (Table 2).

Five statistics were calculated from the detrended series (Biondi and Qeadan 2008): the mean sensitivity (MS), quantifying the year-to-year variability; the first-order auto-correlation coefficient (AC), expressing the influence of previous year growth on current year growth; the mean inter-series correlation coefficient (rbt) providing a synthetic quantitative measure of inter-series heterogeneity among the series; and the expressed population signal (EPS) and signal to noise ratio (SNR), quantifying the degree to which the chronology expressed the population chronology (Mérian and Lebourgeois 2011a, b) (Table 2).

\subsection{Response to the extreme drought 2003}

As BAIs highly varied according to cambial age (Annex 4), the 4298 raw BAIs have been standardized with the regional curve standardization approach (Becker 1989) to remove agerelated signals in growth series before calculating Rt, Rc, and Rs indices. Standardization is achieved by dividing the size of each available ring by the value expected from its cambial age (by fitting smoother functions) in a reference curve (Annex 4). After detrending, the three indices have been calculated for each trees $(n=269)$ (Eqs. (4), (5), and (6)) (Lloret et al. 2011; Pretzsch et al. 2013). Dr corresponds to $\mathrm{BAI}_{\mathrm{d}}$ (i.e., detrended BAIs) for the 2003 drought. PreDr is the mean $\mathrm{BAI}_{\mathrm{d}}$ for the 3 years preceding the drought (2000-2002). This period was chosen to avoid including potential lag effects of the 1998 dry year. PostDr is the mean $\mathrm{BAI}_{\mathrm{d}}$ for the 3 years following the drought (2004-2006). This period was chosen to avoid including the 2007 wet year. 


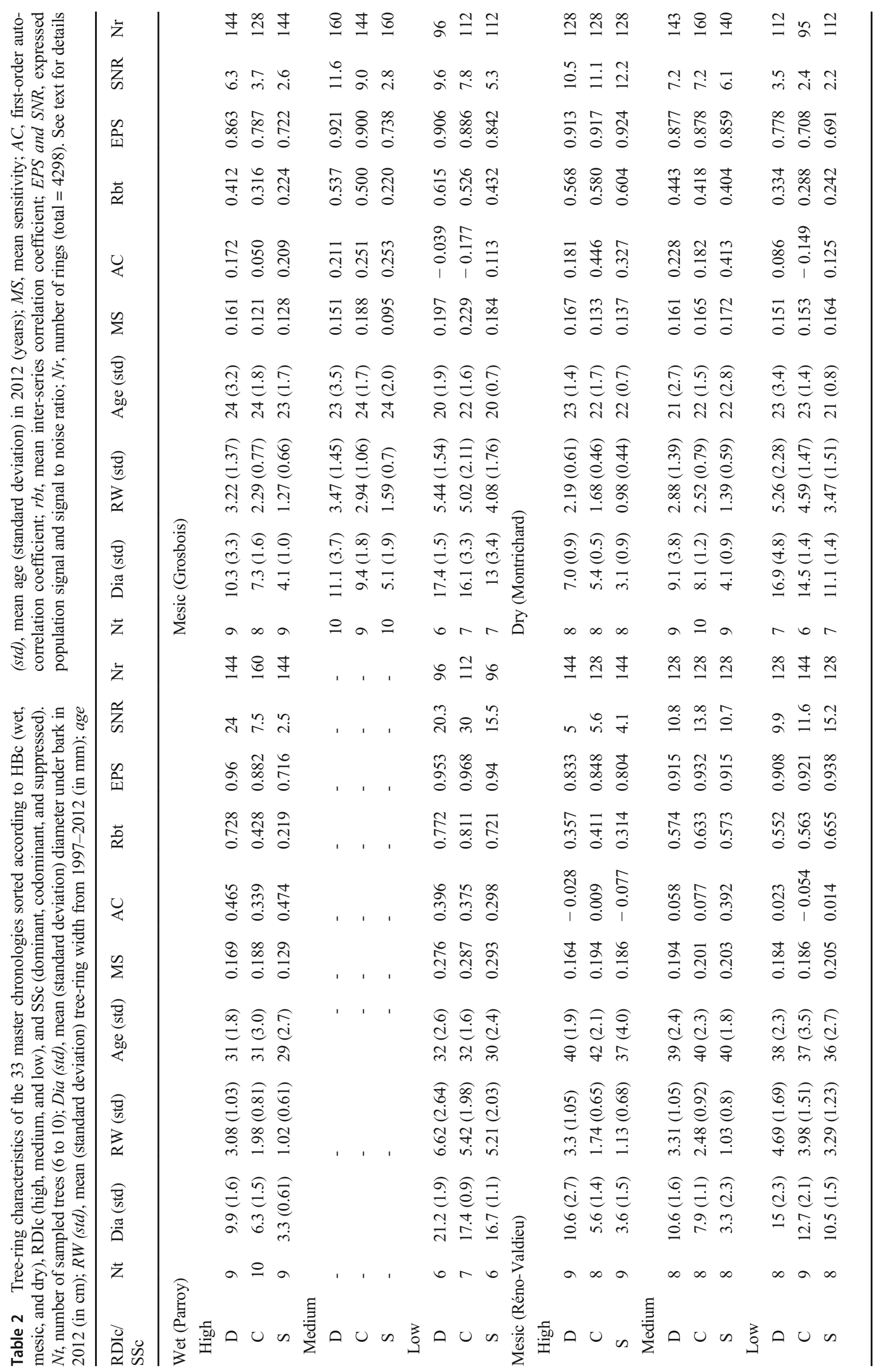


Resistance $(\mathrm{Rt})=\frac{\mathrm{Dr}}{\operatorname{PreDr}}=\frac{\mathrm{BAI}_{\mathrm{d} 2003}}{\mathrm{BAI}_{\mathrm{d} 2000-2002}}$

Resilience $(\mathrm{Rs})=\frac{\text { PostDr }}{\operatorname{PreDr}}=\frac{\text { BAI }_{\mathrm{d} 2004-2006}}{\mathrm{BAI}_{\mathrm{d} 2000-2002}}$

Recovery $(\mathrm{Rc})=\frac{\text { PostDr }}{\mathrm{Dr}}=\frac{\text { BAI }_{\mathrm{d} 2004-2006}}{\mathrm{BAI}_{\mathrm{d} 2003}}$

For Rt, a value of 1 indicates no effect of drought and thus a complete resistance. The further the value drops below 1, the lower the resistance. For Rc, a value of 1 indicates persistence of low growth after the drought. Decreasing Rc indicates a growth decline and increased values $(>1)$ correspond to growth recovery. For Rs, values higher than or equal to 1 correspond to a return at the initial growth level (i.e., level before the stress). Values below 1 show persistence of slow growth.

\subsection{Statistical analyses}

Climate-tree growth relationships were investigated from the period 1997-2012 through the calculation of bootstrapped correlation functions using the 33 growth chronologies as dependent variable (Guiot 1991; Mérian 2012; Zang and Biondi 2013) and a pool of monthly climatic regressors (P, T, HB, VPD, and ED) organized from August of the previous growing season to September of the year in which the ring was formed. The statistical significance of the coefficients was assessed by calculating a $95 \%$ confidence level based on 1000 bootstrap resamples of the data.

To detect to which extent tree-ring statistics differed between the 33 chronologies, we performed a principal component analysis (PCA) on tree-ring characteristics (matrix: rows, 33 chronologies; columns, 7 chronologies statistics valuesRW, age, MS, AC, rbt, EPS, SNR - and 2 climate conditions: TJan and HBs) followed by hierarchical agglomerative clustering (HAC) of the PCA components. Three qualitative variables (HBc, RDIc, and SSc) were added to explain the spatial structure. The (dis)similarity between chronologies was measured as the Euclidean distance and the hierarchy was computed according to Ward's method.

To identify the inter-strata variability of response to climate, we performed a second PCA analysis on the bootstrapped regression coefficients. This latter PCA was calculated - not from the correlation matrix-but from the variance-covariance matrix as descriptors were of similar scale. For both PCA, 95\% confidence ellipses highlighting potential groupings in the factorial maps according to qualitative variables ( $\mathrm{HBc}$, RDIc, and $\mathrm{SSc}$ ) were drawn. PCA analyses were performed with the "FactoMineR" package (Lê and Husson 2008).

To characterize the inter-strata variability of growth response to the 2003 drought, we performed an analysis of variance (ANOVA) followed by Tukey's HSD tests. The ANOVA was used to determine whether there was any statistically significant difference in means of Rt, Rs, and Rc in the three respective different levels of each qualitative class ( $\mathrm{HBc}$, RDIc, and, SSc) (i.e., main effect) and to test for interactions between these factors (i.e., interaction effect). The Tukey HSD tests were used hereafter to highlight which groups differed from the others. Analyses were performed using R version 3.4.4, the "aov" and "lm" functions from base R and the "Ismeans" function from the "Ismeans" package (Lenth 2016).

\section{Results}

\subsection{Climatic variability for the studied period}

From 1997 to 2012, the summer water balance averaged -96 $( \pm 68),-126( \pm 60)$, and $-182( \pm 49) \mathrm{mm}$ for the wet, mesic, and dry sites respectively (Table 1). The common driest years were 2003 (mean value $-215 \mathrm{~mm}$ ) and $1998(-210 \mathrm{~mm})$. On the other hand, 2007 was a wet year $(+11 \mathrm{~mm})$. The anomalies confirmed the exceptional conditions in 1998, 2003, and 2007 (Fig. 1). The droughts in 1998 and 2003 were on average $\sim 1.5$ times higher than normal conditions. The year 2007 was $\sim 2$ times wetter than the average climate. Here, even if 1998 was a dry year, we excluded it for the analysis of Rt, Rs, and Rc as this year was too close to the start of the application of the RDI treatments (between 1995 and 1997 depending on the site).

The 3 years (2000-2001-2002) preceding the 2003 drought corresponded to rather humid years for all sites (positive anomalies) except for the wet site in 2002. For this site, the year was already characterized by a slight drought relative to mean conditions (Fig. 1). After the drought (2004-20052006), the climate conditions returned rather than the normal for the wet site but remained dry for the dry and mesic sites (negative anomalies). For these sites, 2004 was rather than the normal but 2005 and 2006 appeared worst. The year 2005 was even worse than in 2003. The evolution of the cumulated summer evaporation deficit and anomalies (EDs) showed similar results (data not shown).

\subsection{Radial growth and chronologies statistics}

Radial growth was strongly affected by stand density and social status (Table 2). Trees from medium-density stands grew an average $\sim 1.3$ times faster than trees from dense stands, while trees from low-density stands grew $\sim 2.5$ times faster than trees from dense stands. Dominant trees grew respectively $\sim 1.5$ and $\sim 1.8$ times faster than codominant and suppressed trees. In the high-density stands, where the difference in growth between social statuses was maximum, dominant trees grew $\sim 1.7$ and $\sim 2.7$ times faster than codominant and suppressed trees, respectively. Lastly, the dry site had 
Fig. 1 Summer water balance (HBs) anomalies from 1997 to 2012 for each $\mathrm{HBc}$ (wet, mesic and dry; mean values in $\mathrm{mm}$ in parenthesis). The HBs was calculated as the sum from June to August (in mm). Negative values correspond to conditions drier than normal (wetter otherwise). Wet, Parroy; mesic, mean for Grosbois and Réno-Valdieu; dry, Montrichard. See text for details

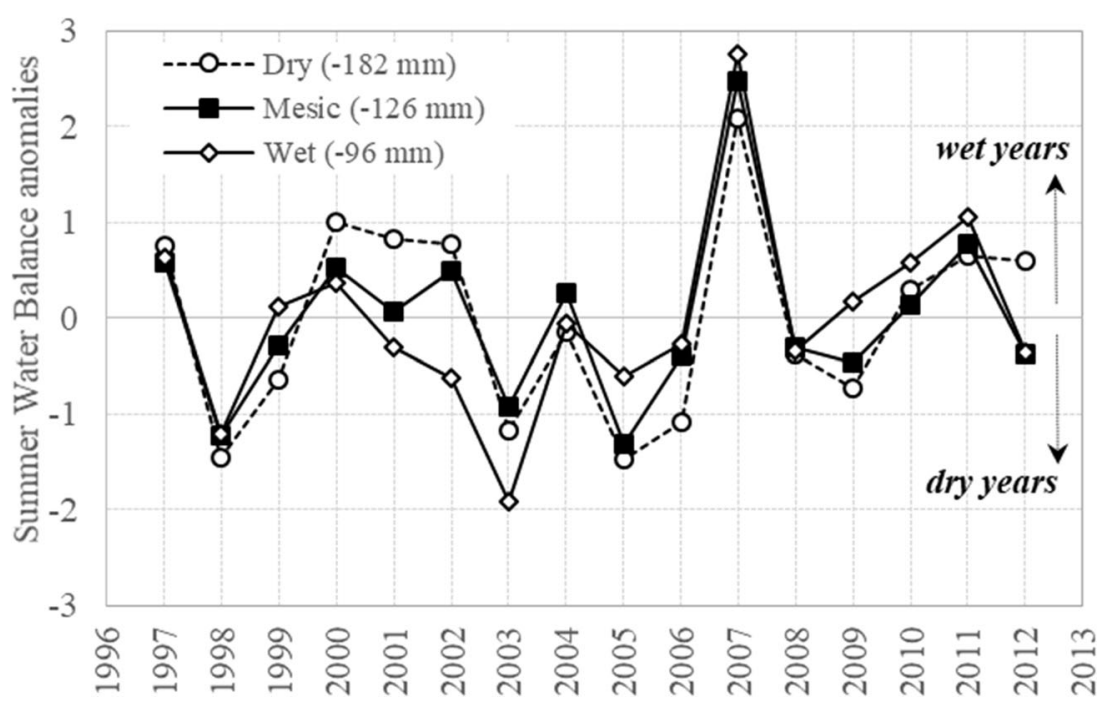

lower growth than the wet site, independently of the level of competition (Table 2).

PCA and HAC performed on chronologies statistics clearly classified wet, mesic, and dry stands in different clusters and in a less extend low- and high-density treatments (Table 2 and Annex 5). The effect of social status was no discriminant (Annex 5). Finally, growth, MS, and Rbt were found lower for dry sites and in a less extend in high-density stands (Table 2 and Annex 5). This suggested that the strength of the climate signal and the homogeneity of the response decreased with water constraints and competition.

\subsection{Climate-growth relationships over the 1997-2012 period}

PCA on bootstrapped correlation coefficients (BCC) evidenced a clear clustering according to $\mathrm{HBc}$ (Fig. 2b). On the other hand, neither RDIc nor SSc modulated the climategrowth relationships (Fig. $2 \mathrm{c}$ and $\mathrm{d}$ ). We found a positive effect of warm winter (mean temperature in January or February) common to all the clusters. For dry site, tree growth varied also highly with spring (May and June) precipitation (mean BCC with PMay and PJune $=0.654$ and 0.281) (Fig. $2 \mathrm{a})$. For mesic sites, trees responded positively to previous autumn and current summer precipitation (mean BCC with pPSeptember $=0.598$; PJuly $=0.334$; PAugust $=0.270$ ) . Lastly, under the wettest site, the effect of precipitation during the growing season appeared not significant, the growth depending highly on previous autumn and current late winter precipitation (mean $\mathrm{BCC}$ with pPSeptember $=0.588$; PMarch $=0.637$ ) and early spring temperature (mean BCC with TMay $=0.596$ ) (Fig. 2a). Similar results have been observed with the climatic regressors ED, HB, and VPD (data not shown).

\subsection{Immediate and delayed effects of the 2003 drought}

Stand density and water balance both had significant effects on the drought response with a clear interaction between both factors (Table 3 ).

On wet site, Rt, Rs, and Rc were below one and below the values observed on mesic and dry sites (Fig. 3) but the three indices were lowest in high-density stands (means 0.65 vs 0.81 ) (Fig. 3 and Table 4). Thus, under these conditions, the drought effect was important and both Rs and Rc were incomplete.

On mesic sites, Rt, Rs, and Rc averaged systematically higher for low-density stands and were above one suggesting no drought effect (Fig. 3 and Table 4). No significant difference has been observed between high- and medium-density stands which were both more affected by the drought than the low-density stands (Rt values close to 1 and incomplete Rs and Rc; values below 1).

On dry site, Rt, Rs, and Rc averaged higher for low-density stands (Fig. 3 and Table 4). Values were above one suggesting no drought effect and a complete Rs and Rc. After the drought, medium-density stands also recovered (Rc values above one) but not to their initial growth (Rs below 1). Lastly, the maximum differences among the three stand densities were observed on a dry site. Thus, trees from lowdensity stands grew an average twice than trees from dense stands after the drought (Rs and Rc 1.20 vs 0.6 ) (Fig. 3).

For the social status, the differential responses between $\mathrm{SSc}$ appeared not much significant (Tables 3 and 4 and Annex 6). The only significant difference occurred under mesic sites with lower Rs values for suppressed trees compared with dominant and codominant ones and lower Rc values compared with dominant trees (Table 4). Under the two other water availability conditions, it appeared that all trees were impacted irrespective of their social status (Annex 6). 

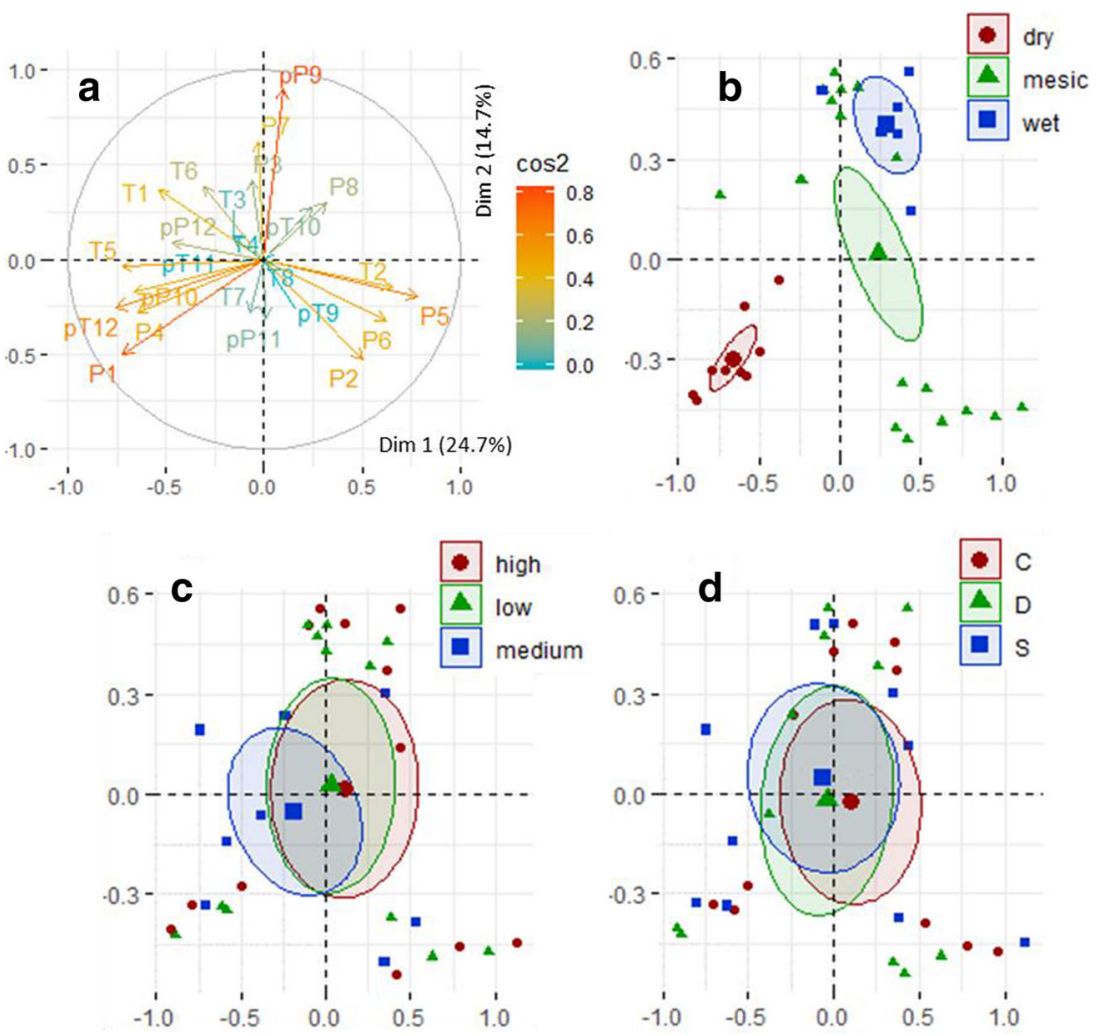

Fig. 2 Structuring of the 33 correlation functions. The analyses have been performed on the significant BCC calculated from the common period 1997-2012. a Scatter plot of principal component analysis (PCA, dim 1 and 2 ) performed on the matrix (33 correlation functions $* 24$ climatic variables) (here climatic variables). $P$ and $T$, Precipitation and Temperature; number of the month; $p$, previous month. b-d Scatter plot of principal component analysis (PCA, dim 1 and 2 with the 95\% ellipse

confidence) for the 33 correlation functions for each qualitative variables: b HBc (dry, mesic, wet; $r^{2}$ with $\operatorname{dim} 1$ and $\operatorname{dim} 2=0.333$ and $0.362, p$ value $=0.002$ and 0.001 ); $\mathbf{c}$ RDIc (high, medium, low); $\mathbf{d ~ S S c ~ ( d o m i n a n t , ~}$ codominant, suppressed). A complete disjunction between the $95 \%$ ellipse confidence means that the response to mean climate are different between each modality of each qualitative variable. See text for details

Finally, we observed higher Rt, Rs, and Rc values for lowdensity stands all the more that the conditions were dry. Only trees growing under low competition pressure on the less favorable sites (dry and mesic) totally recovered their growth at their initial level after the 2003 drought; the maximum range of Rs and Rc values between RDIc having been observed for the driest site (Fig. 3).

\section{Discussion}

\subsection{Overall climatic response pattern}

As observed in previous studies, tree-ring characteristics of sessile oak changed with site water availability (Becker et al. 1996; Bergès et al. 2008; Lévy et al. 1992; Timbal and Aussenac 1996) and competition (Guilley et al. 1999; Zhang et al. 1993). Generally, the growth, the year-to-year variability (i.e., MS), and the homogeneity of the response to climate within stand (i.e., Rbt, SNR) all decreased with increasing local constraints (drier conditions, higher competition).
Concerning the year-to-year variability, our results agree with the global observation for oak stands in northern France with lower MS values under drier/warmer climate (Mérian et al. 2011). Our results are also consistent with the general climatic pattern observed for this species: positive influence of high precipitation during previous late summer, high winter temperature, and high spring precipitation during the current year (Friedrichs et al. 2009; Lebourgeois et al. 2004; Mérian et al. 2011). The underlying ecophysiological explanation of these observations is now well documented. Previous late summer conditions can improve carbon storage facilitating oak's annual growth (Barbaroux et al. 2003; Davi et al. 2009; Guillemot et al. 2015; Michelot et al. 2012; Perez-de-Lis et al. 2017). Higher winter temperature can modify cambial functioning or leaf phenology (Delpierre et al. 2016) which in return can change the timing and the level of growth in the following growing season. Reduced embolism has also been mentioned to explain the positive effect of warm winter temperature on tree growth (Tyree and Cochard 1996). Lastly, during the season, a good water supply modifies the phenology of wood formation (Delpierre et al. 2016). 
Table 3 Results of the ANOVA showing the direct and the interaction effects of RDIc, $\mathrm{HBc}$, and SSc on the three indices of growth response to drought (resistance, resilience, and recovery; $n=269$ trees). The Tukey multiple comparisons of means. The number of * corresponds to the $\mathrm{p}$ values $(*, * *$, and ***: $0.05,0.01$, and 0.001 ).

See text for details

\begin{tabular}{lllllll}
\hline & & Df & Sum Sq & Mean Sq & $F$ value & $\operatorname{Pr}(>F)$ \\
\hline Resistance (Rt) & RDIc & 2 & 2.005 & 1.0025 & 12.33 & $<0.0000^{* * *}$ \\
& HBc & 2 & 5.165 & 2.5826 & 31.765 & $<0.0000^{* * * *}$ \\
& SSc & 2 & 0.133 & 0.0664 & 0.817 & 0.4429 \\
& RDIc:HBc & 3 & 1.121 & 0.3737 & 4.596 & $0.0038^{* *}$ \\
& RDIc:SSc & 4 & 0.13 & 0.0325 & 0.4 & 0.8088 \\
Resilience (Rs) & HBc:SSc & 4 & 0.078 & 0.0195 & 0.24 & 0.9157 \\
& Residuals & 251 & 20.407 & 0.0813 & & \\
& RDIc & 2 & 10.422 & 5.211 & 67.346 & $<0.0000^{* * *}$ \\
& HBc & 2 & 5.168 & 2.584 & 33.397 & $<0.0000^{* * *}$ \\
& SSc & 2 & 0.958 & 0.479 & 6.189 & $0.00238^{* *}$ \\
& RDIc:HBc & 3 & 1.5 & 0.5 & 6.464 & $0.00031^{* * *}$ \\
& RDIc:SSc & 4 & 0.691 & 0.173 & 2.234 & 0.06592 \\
& HBc:SSc & 4 & 0.641 & 0.16 & 2.072 & 0.08502 \\
& Residuals & 251 & 19.422 & 0.077 & & \\
Recovery (Rc) & RDIc & 2 & 4.91 & 2.4573 & 18.267 & $<0.0000^{* * *}$ \\
& HBc & 2 & 0.85 & 0.4225 & 3.141 & $<0.0000^{* *}$ \\
& SSc & 2 & 1.14 & 0.5703 & 4.24 & $0.01546 * *$ \\
& RDIc:HBc & 3 & 2.85 & 0.9485 & 7.051 & $0.00014 * * *$ \\
& RDIc:SSc & 4 & 0.84 & 0.2089 & 1.553 & 0.18743 \\
& HBc:SSc & 4 & 0.72 & 0.1808 & 1.344 & 0.25414 \\
& Residuals & 251 & 33.76 & 0.1345 & & \\
\hline
\end{tabular}

\subsection{Effects of site water balance and stand density on climate-growth relationships}

We confirmed that trees grown in drier sites respond differently as climate-growth relationships highly changed from wet (i.e., semi-continental climate) to dry sites (i.e., altered oceanic climate). This pattern is in agreement with a previous large-scale study performed in oak temperate forests and confirms that the year-to-year variability and the tree responses are largely organized along the wide-scale climatic gradients that change the climate drivers of tree ring (Mérian et al. 2011). It may also be the reflection of both high local adaptability and high growth plasticity (Kremer and Petit 1993) which would explain the interaction between sites and tree response to year-to-year climate variability.

We rejected the hypothesis that stand competition modulates the drivers of the year-to-year growth variations. Indeed, neither stand density nor the social position of a tree within a stand modified the climate drivers of oak growth: similar season and comparable strength of the correlations. This result agrees with a previous analysis performed in the even-aged sessile oak stands ( 100 years) used by Trouvé et al. (2016). Thus, for a dry site in western France (summer water balance - $168 \mathrm{~mm}$ ), similar climatic drivers have been observed from 1960-2012 for mediumand high-density stands (RDI 0.4 and 1) (i.e., a major role of spring precipitation) (Schmitt 2017). The absence of stand density effect on the climate-growth relationships is still debated and the literature on the subject remains contradictory with no effect (Novak et al. 2010; Pérez-de-Lis et al. 2011) or lower sensitivity to drought in lower-density stands (D'Amato et al. 2013; Magruder et al. 2013; Martin-Benito et al. 2010; MartinBenito et al. 2011). On the other hand, the study of GeaIzquierdo et al. (2009) led in Quercus ilex showed that highdensity stands responded to similar climatic factors as lowdensity stands, but their response was generally weaker. Concerning the social status, results appeared also highly contrasted with a stronger climatic effect on dominant trees (Olivar et al. 2012; Sánchez-Salgueroa et al. 2015), no clear difference between social classes (Meyer and Bräker 2001) or differences depending on stand basal area (Lebourgeois et al. 2014). Similar various results have been observed for studies dealing with tree size (i.e., raw diameter classes) (Castagneri et al. 2012; Mérian and Lebourgeois 2011a, b; Zang et al. 2012). Lastly, all these studies show that it is difficult to draw a common pattern of the effect of competition on the climatetree growth relationships.

\subsection{Site water balance and stand density effects on resistance, recovery, and resilience}

We confirmed the hypothesis that trees growing at greater stand density level have lower resistance, resilience, and recovery than trees undergoing lower competition. Indeed, we observed higher Rt, Rs, and Rc values for low-density stands 
Fig. 3 Boxplot for resistance, resilience, and recovery according to $\mathrm{HBc}$ (dry, mesic, wet) and stratified by RDIc (high, medium, low). The open circle corresponds to the mean value of the variable for each modality and the dotted line to the overall mean. Means and $p$ value are presented in Table 4 (Tukey's HSD tests)
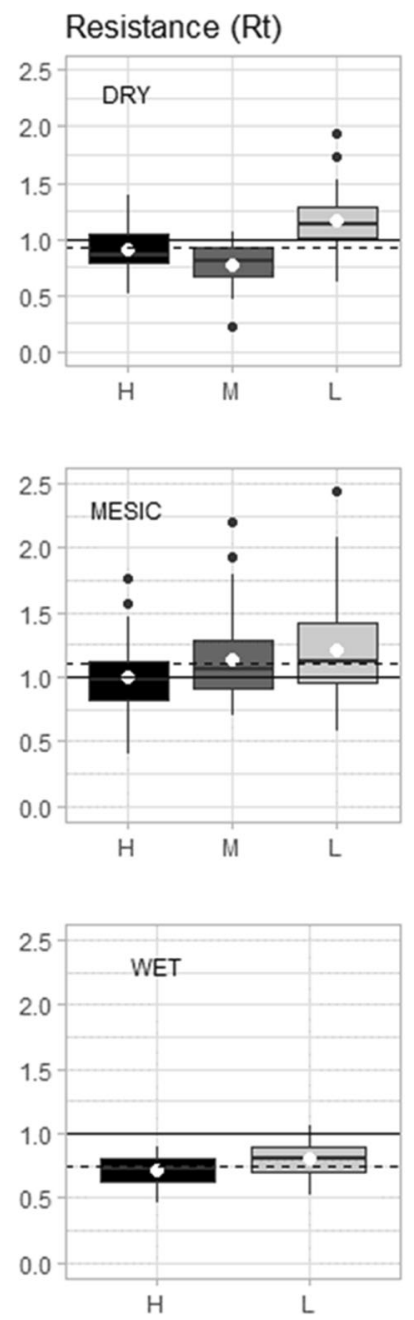

Resilience (Rs)
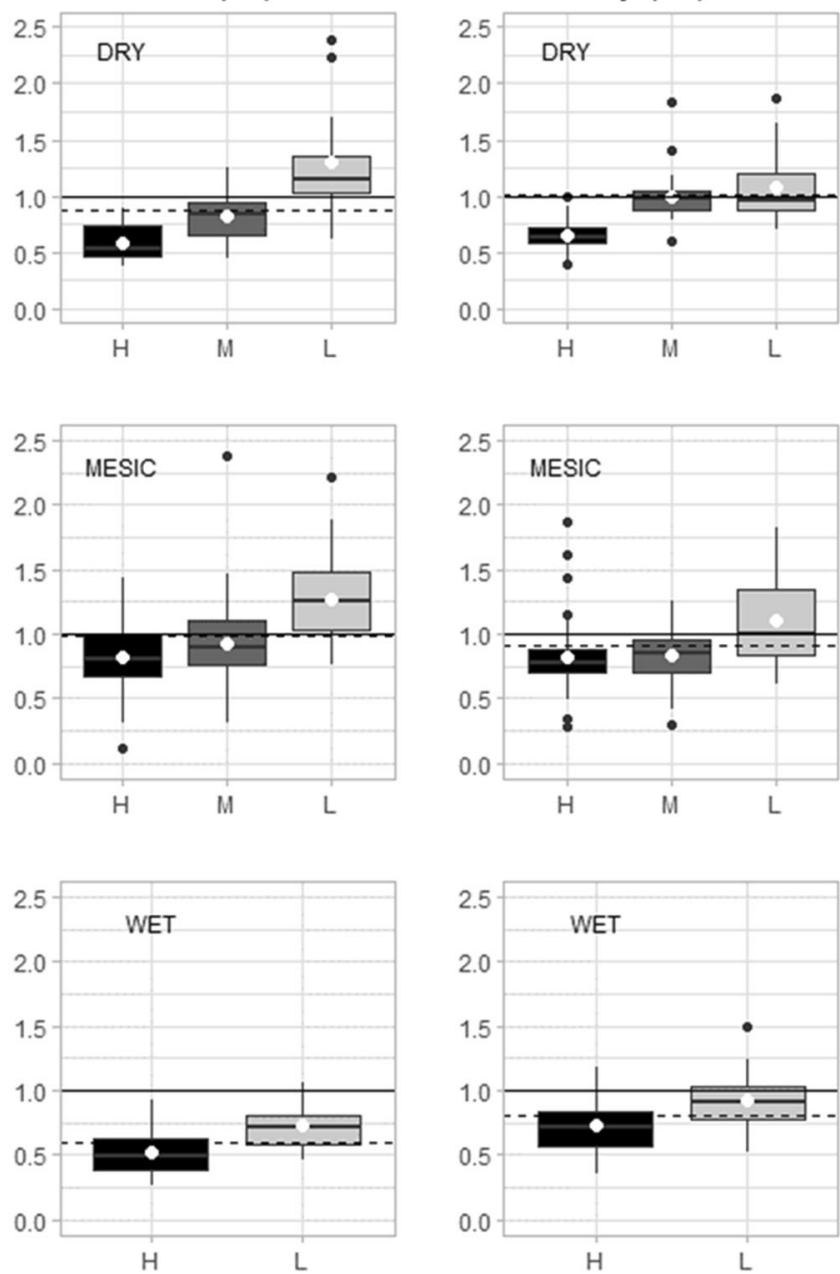

Recovery (Rc)

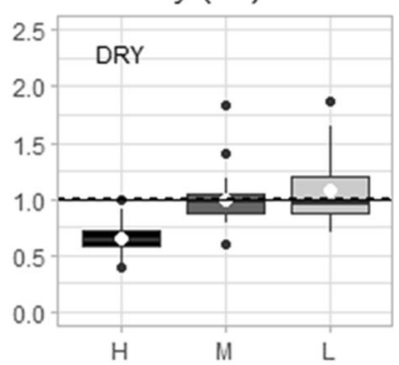

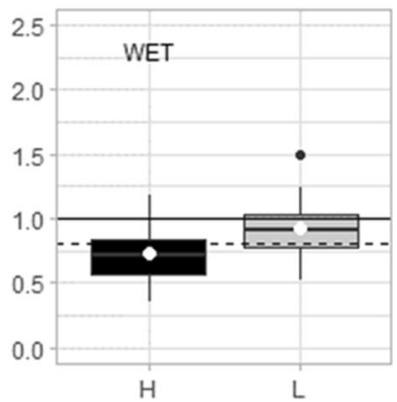

Table 4 Results of the ANOVA for each HBc (dry, mesic, and wet) showing the direct effects of RDIc (high, medium, and low) and SSc (dominant, codominant, and suppressed) on the three indices of growth response (values in italics) to drought (resistance, resilience, and recovery; = 269 trees). The Tukey multiple comparisons of means. The table gives $p$ values (significant values in bold). See text for details and Fig. 3 and Annex 6

\begin{tabular}{|c|c|c|c|c|c|c|c|c|c|c|}
\hline & & \multicolumn{3}{|l|}{ DRY } & \multicolumn{3}{|l|}{ MESIC } & \multicolumn{3}{|l|}{ WET } \\
\hline & & Rt & Rs & $\mathrm{Rc}$ & Rt & Rs & $\mathrm{Rc}$ & Rt & Rs & $\mathrm{Rc}$ \\
\hline \multirow[t]{6}{*}{ RDIc } & H-M & 0.1359 & 0.0153 & 0.0031 & 0.0968 & 0.1481 & 0.9888 & - & - & - \\
\hline & $\mathrm{H}-\mathrm{L}$ & 0.0018 & 0.0001 & 0.0161 & 0.0052 & $<0.0001$ & $<0.0001$ & 0.0385 & 0.0003 & 0.0031 \\
\hline & M-L & $<0.0001$ & $<0.0001$ & 0.9504 & 0.4672 & $<0.0001$ & $<0.0001$ & - & - & - \\
\hline & $\mathrm{H}$ & $0.904 a$ & $0.578 a$ & $0.649 a$ & $1.002 a$ & $0.814 a$ & $0.823 a$ & $0.714 a$ & $0.518 a$ & $0.725 a$ \\
\hline & M & $0.774 a$ & $0.821 b$ & $1.204 b$ & $1.135 a b$ & $0.926 a$ & $0.831 a$ & - & - & - \\
\hline & $\mathrm{L}$ & $1.165 b$ & $1.303 c$ & $1.152 b$ & $1.214 b$ & $1.268 b$ & $1.105 b$ & $0.799 b$ & $0.723 b$ & $0.923 b$ \\
\hline \multirow[t]{3}{*}{$\mathrm{SSc}$} & D-C & 0.9956 & 0.5104 & 0.1997 & 0.8126 & 0.5221 & 0.7725 & 0.9921 & 0.9514 & 0.9198 \\
\hline & D-S & 0.9941 & 0.9868 & 0.5636 & 0.3648 & 0.0028 & 0.0173 & 0.9999 & 0.7597 & 0.6588 \\
\hline & C-S & 0.9795 & 0.6068 & 0.7588 & 0.7493 & 0.0698 & 0.1059 & 0.9936 & 0.9036 & 0.8659 \\
\hline
\end{tabular}

The table gives $p$ values (significant values in bold) and the different letters after the indices of growth response to drought (values in italic) indicate the significant differences between the indices 
and all the more that the conditions were dry. Thus, the effect of the drought was more marked on the "best" sites and the pre-drought growth level was not fully recovered 3 years later under these conditions. Thus, the strength of the lagged effect of the drought increased with stand density and with the improvement of the ecological conditions.

Our results confirm that high competition between trees appears to limit the ability of forest trees to cope with extreme climate and that stand density control can ensure continuous tree growth during stress and improve radial growth recovery after an extreme climatic event (Kohler et al. 2010; Lloret et al. 2011; Misson et al. 2003a, b; Sohn et al. 2013; Sohn et al. 2012; Sohn et al. 2016). Here, the ability to cope with an extreme drought is low for trees growing under the wettest sites, and reducing stand density only slightly reduces the negative effect of the drought on tree growth. In drier sites, trees appear to be better able to resist to an extreme drought, and reducing stand density can strongly increase tree's ability to recover after the stress. Close interactions between site water balance and tree response to drought are often observed in the literature: in old even-aged stands of sessile oak in France, recovery after the severe drought of 1976 was found lower in wetter than in drier sites (Trouvé et al. 2016). On the other hand, resistance was found higher on wetter than in drier sites for Picea abies in Germany (Kohler et al. 2010; Misson et al., 2003a, b; Sohn et al. 2013; Sohn et al. 2012) and in broadleaved forest ecosystems (Pinus virginiana, Liriodendron tulipifera, Quercus alba, Q. velutina, Carya glabra, and Nyssa sylvatica) of northern Virginia (Orwig and Abrams 1997).

The social status effect remains rather controversial (Lebourgeois et al. 2014). Many studies showed a marked effect of social status for oaks (Liu and Muller 1993; Trouvé et al. 2016) or coniferous species (Martin-Benito et al. 2008; Pichler and Oberhuber 2007; Van Den Brakel and Visser 1996; Vose and Swank 1994) whereas others underlined an unclear or no effect (Merlin et al. 2015; Orwig and Abrams 1997; Zang et al. 2012). In our study, we showed no strong difference among social statuses. To explain this unclear effect of tree social status, we can hypothesize that the tree young age might partly offset the effect of social position. Thus, we may expect an adjustment of the response over time linked to tree development (rooting, tree-level water demand...) and a more pronounced effect of social differentiation in older trees (Trouvé et al. 2016).

\subsection{Consequences for forest management}

In our study, all stands have been subjected to an exceptional summer water deficit during 2003. Nevertheless, the increase in summer water deficit relative to mean site conditions was higher in the wet sites and 2002 was also a relatively dry year (Fig. 1). This may explain the lower Rt, Rs, and Rc of trees growing in the wettest site conditions. Remarkably, although the climate returned to the normal conditions on wet sites and remained rather dry for the other stands (Fig. 1), trees in the wetter site did not fully recover their pre-drought growth level even 3 years after the stress. All these results also confirm the findings of Trouvé et al. (2016) that tree response to an extreme event is more closely related to the relative increase in summer deficit (higher in the wet sites) than to absolute summer conditions (higher in the dry sites) and that drought intensity should be defined in relation to average climatic conditions. This also highlights the major role of acclimation and adaptation of tree population to local climate (Saenz-Romero et al. 2017). Drier sites are more likely to favor individual acclimation and cross-generation adaptation of trees to drought (Bréda and Badeau 2008) and trees growing on wetter sites appear to be more vulnerable to drought events than drier ones (Martin-Benito et al. 2008; Martinez-Vilalta et al. 2012; Trouvé et al. 2016).

This finding suggests that the most important impact of climate change on tree growth might appear in areas where the oaks are less adapted or acclimated to dry conditions and not at the southern margin of species distribution where trees grow under more restrictive conditions. From a silviculture point of view, reducing stand density attenuated slightly the sensitivity to the climate without changing the climatic drivers of tree growth but can efficiently improve drought resistance, recovery, and resilience particularly in the drier sites. Here, we experienced a wide and original range of RDIc and showed that the stronger effects were obtained for the lower values. Thus, our study confirms that heavy thinning is required to maintain high growth before, during, and after drought events (Sohn et al. 2016). As RDI values average around 0.5 in French managed oak forests (Seynave et al. 2018; Trouvé et al. 2019), new silvicultural prescriptions should be done to reach a good state of "potential resistance, resilience, and recovery to extreme events." Even if low RDI values $(<0.5)$ seem to be a better option to adapt forest management to drought events, forest managers would have to deal with changes in tree architecture and sprouts which might impact the quality and the economic value of wood (Trouvé et al. 2014; Trouvé et al. 2015; Trouvé et al. 2019). As the tree response to thinning may differ for recurrent droughts than span many years, the long-term monitoring appears crucial to clearly address the benefits of thinning for both sustainable growth and timber quality.

\section{Conclusion}

Sessile oak tree's response to mean climate and extreme events depends mostly on site water balance. Stand density did not change the climate drivers of tree growth but significantly modulated the tree's capacity to cope with extreme 


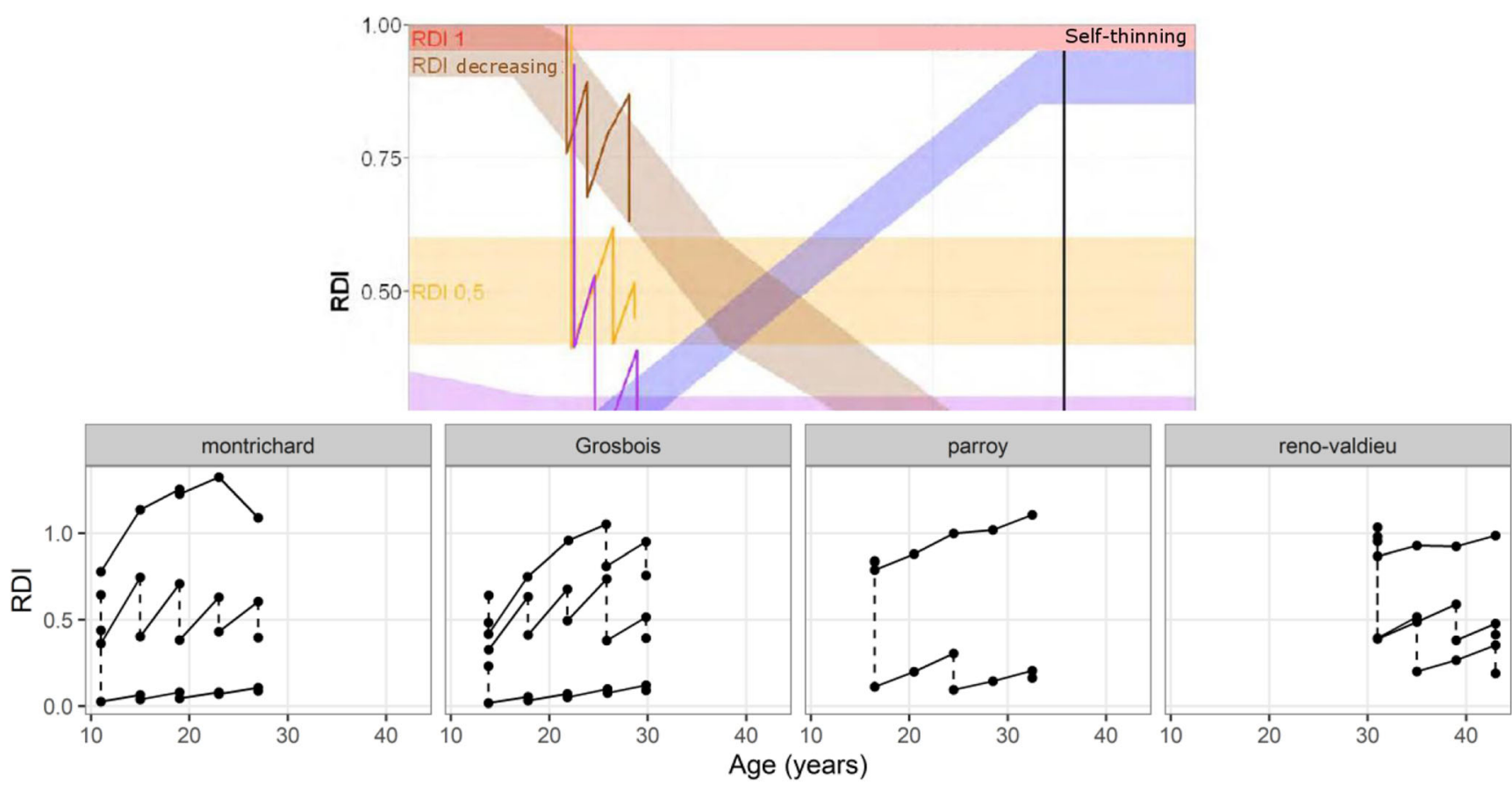

Fig. 4 Theoretical (top) and observed (bottom) trajectories in the sessile oak GIS Coop network. Colored bands dene the target RDI-age trajectories, while the solid lines are an example of actual trajectories. Two particular treatments stand out: the "increasing" treatment, which starts at low RDI and increases with stand age and the "decreasing"

drought. The major impact of the silviculture is to increase resistance, recovery, and resilience, particularly on drier sites. The relative increase in the summer drought, which is often lower in dry sites, seems to be more relevant than absolute summer drought to determine drought intensity and severity. Reducing stand density might help trees to cope with climate change but lower densities than usual should be done (typically RDI < 0.5) if we want to reach sufficient levels of Rt, Rc, and Rs to extreme events. Foresters must find the best compromise between increasing forest resistance to drought, maintaining stand production, and reducing timber quality.

Acknowledgments We would like to thank all the GIS Coop members from many different organisms (INRAE, APT, ONF, FCBA, CPFA, CNPF-IDF) who participate in the data collection, manage the database, and assist in the development of the network. We are in particular grateful to the "Chênes" and "CoopEco" groups.

Authors' Contribution François Lebourgeois and Ingrid Seynave conceptualized and coordinated this research project using GIS Coop networks and co-wrote the paper; Ingrid Seynave designed and managed database, coordinated the works on the network sampling scheme, and the acquisition of ecological data; Raphaël Trouvé supervised the coring and the tree-ring width measurements. Anna Schmitt and François Lebourgeois analyzed data, and coordinated and wrote the paper. Ingrid Seynave and Raphaël Trouvé co-wrote, checked, and corrected the paper.

Funding information The GIS Coop networks benefits from the financial support of the French Ministry of Agriculture and Forest since 1994. As partner of GIS Coop, AgroParisTech (formerly ENGREF), CPFA, IDF, FCBA (formerly treatment which starts at RDI $=1$ and decreases with stand age. Note that the stands analyzed are still young $(\sim 30$ years $)$, and that for the purpose of our analyses, the increasing treatments are similar to the $\mathrm{RDI}=0.25$ treatments while the decreasing treatments are similar to the RDI $=1$ treatments (modified from Trouvé et al. 2019)

Afocel), INRAE (formerly INRA and Irstea), and ONF support the GIS Coop and have made available more than 175 people since 1994 . The projects below also contributed to GIS Coop networks and to this study: ADAREEX (17VN04, 2016-2018); RMT AFORCE, Ministère en charge des Forêts, France Bois Forêt, Labex ARBRE CoopEco (2012-2017); Ministère de 1 'Agriculture, de l'Agroalimentaire et de la Forêt, Office National des Forêts; E16/2012, E31/ 2012, E22/2015.

Data availability The datasets generated during and/or analyzed during the current study are available from the GIS Coop members on reasonable request.

\section{Compliance with ethical standards}

Conflict of interest The authors declare that they have no conflict of interest.

\section{Appendix}

\section{Annex 1}

Thinning regimes and RDI trajectories for the GIS Coop network. Our data originate from a long-term experimental network in France belonging to the "Coopérative de données sur la croissance des peuplements forestiers" (GIS Coop). GIS Coop is a long-term national cooperative research venture among French forest institutions specifically designed to explore the effect of large density gradients, from open-grown trees to self-thinning stands on the forest dynamics of even- 

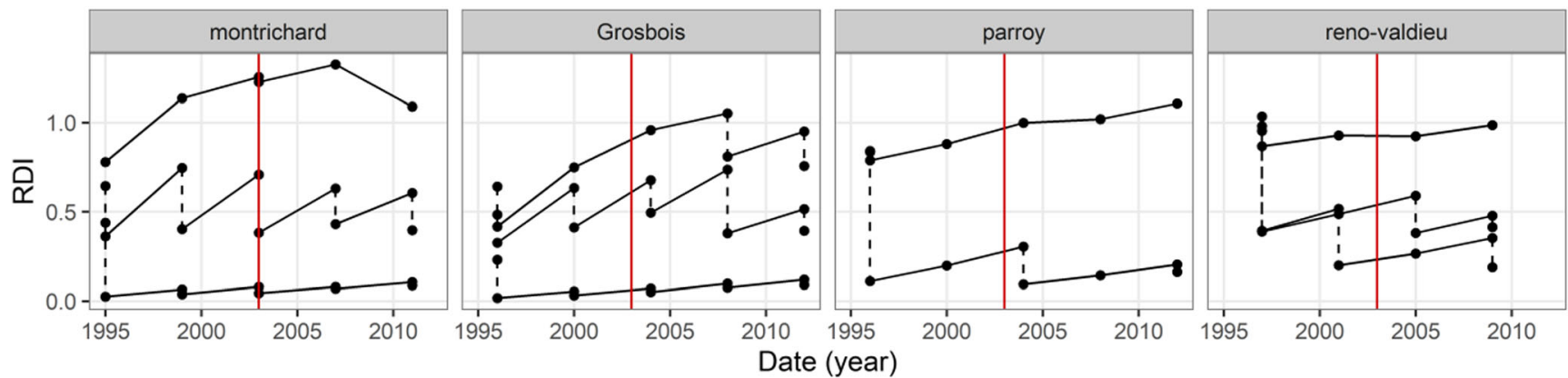

Fig. 5 Examples of observed trajectories "RDI versus year" in the sessile oak GIS Coop network. The line represents the year 2003

aged stands across a range of environmental gradients. The network has been thoroughly presented in a previous paper published in AFS in 2018 (Seynave et al. 2018). Each trial corresponds to a set of experimental plots $(0.36 \mathrm{ha})$ of the same age ( $\sim 10$ to 40 years), measured every 4 years, and subjected to different thinning regimes defined through a relative density index scenario. Stand thinning was triggered at the beginning of a period (after each measurement) whenever the relative stand density of the plot was above the target relative density defined in its thinning regime. Theoretical and observed trajectories "RDI versus age" for the silvicultural network are shown in Fig. 4, while observed trajectories "RDI versus year" for the sites and plots that were used in the paper are shown in Fig. 5.

Tree thinning in the experiment was done from below: smaller than average trees were removed during thinning. We can further quantify the type of thinning by the $k$ factor, computed as the ratio between $\mathrm{Dg}$ of thinned trees to $\mathrm{Dg}$ before thinning. It is equal to 0.91 in our data (Fig. 6)

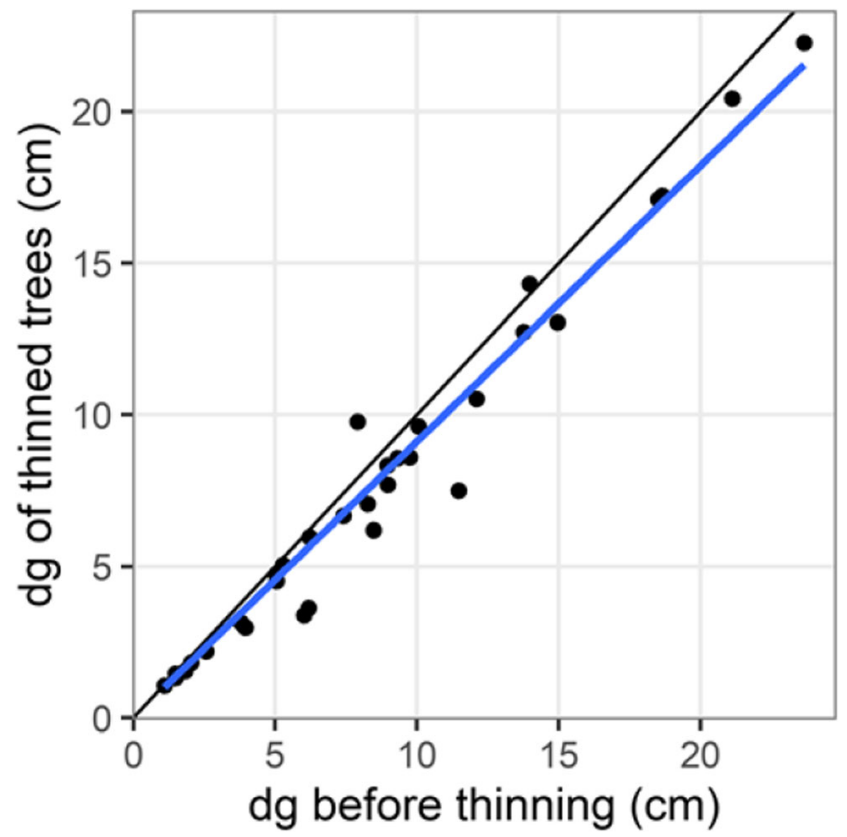

Fig. 6 Characterization of the thinning type using the $k$ factor defined by the ratio between Dg of thinned trees and Dg before thinning. Here the value is 0.91

\section{Annex 2}

Relative diameter changes (\%) for SSc according to stand density and water balance classes (RDIc and HBc). The level 100\% corresponds to the dominant (D) trees. $\mathrm{C}$ and $\mathrm{S}$ represent codominant and suppressed trees. The mean $( \pm$ std $)$ diameter of D, $\mathrm{C}$, and $\mathrm{S}$ trees for each modality is presented in Table 2

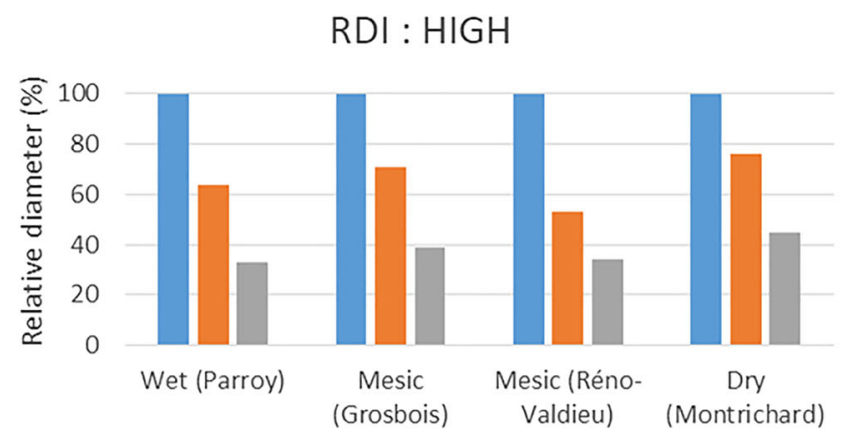

RDI : MEDIUM

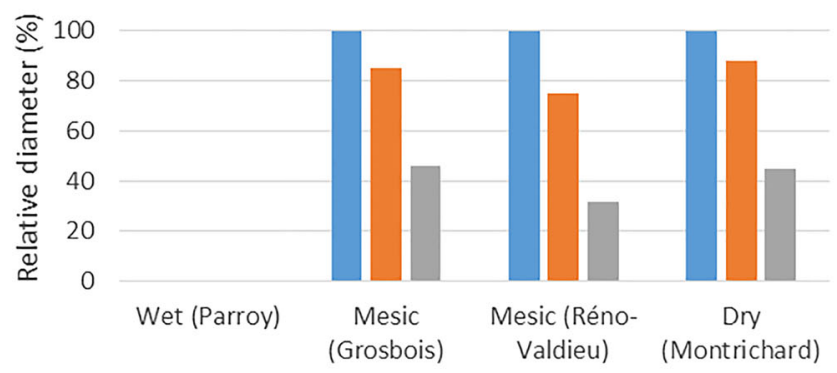

RDI : LOW

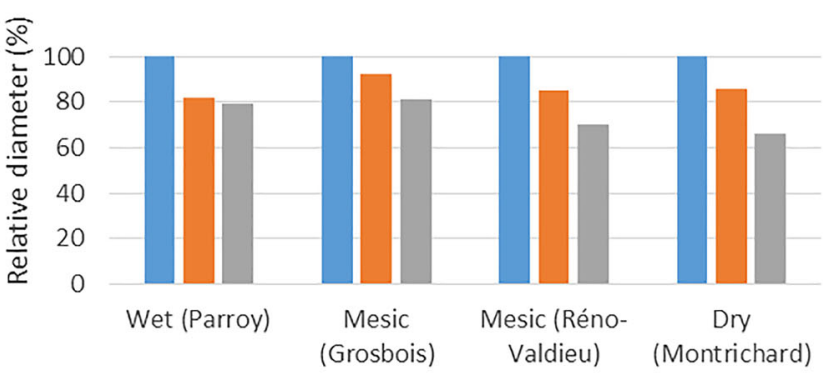

$\square \mathrm{D} \square \mathrm{C}$ 


\section{Annex 3}

Standardized master chronologies (unitless indices) used to analyze the climate-growth relationships. H, M, and L repre- sent high-, medium-, and low-density stands, respectively; D, $\mathrm{C}$, and $\mathrm{S}$ represent dominant, codominant, and suppressed trees, respectively

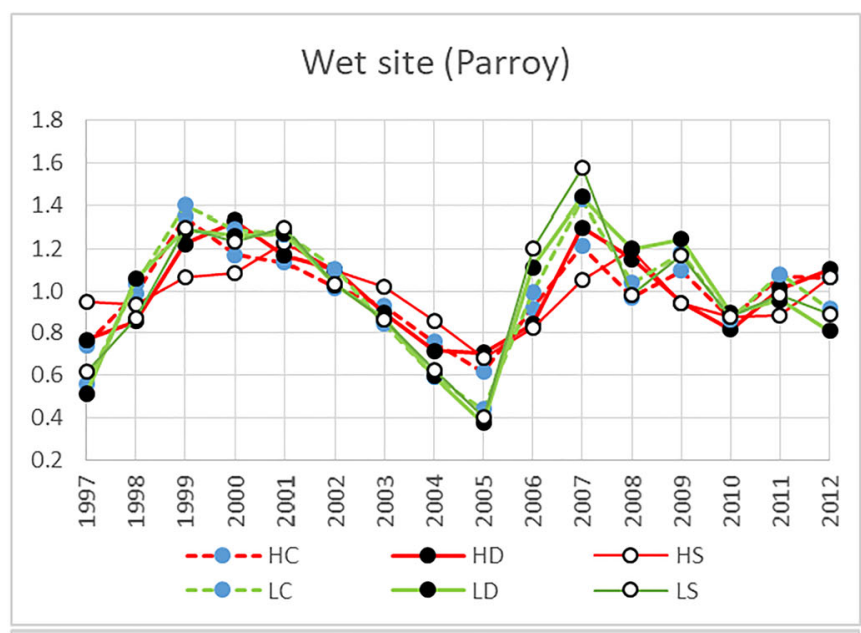

Dry site (MontRichard)

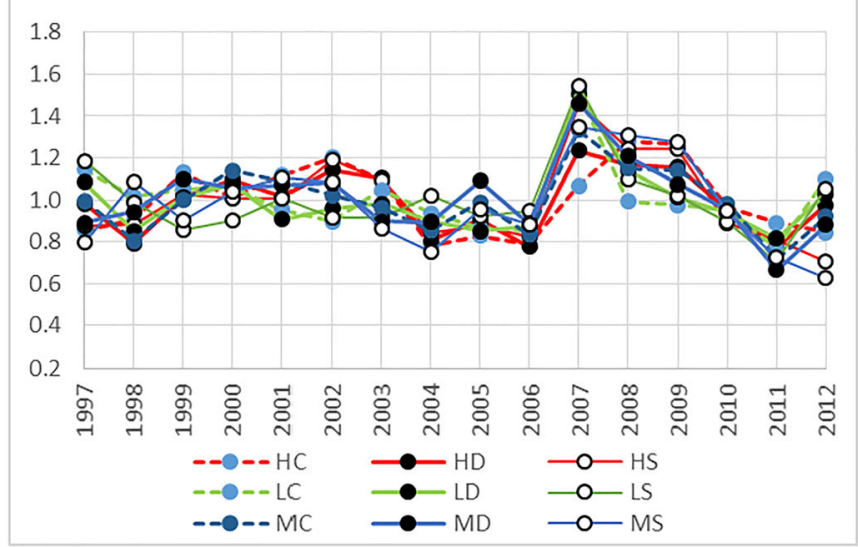

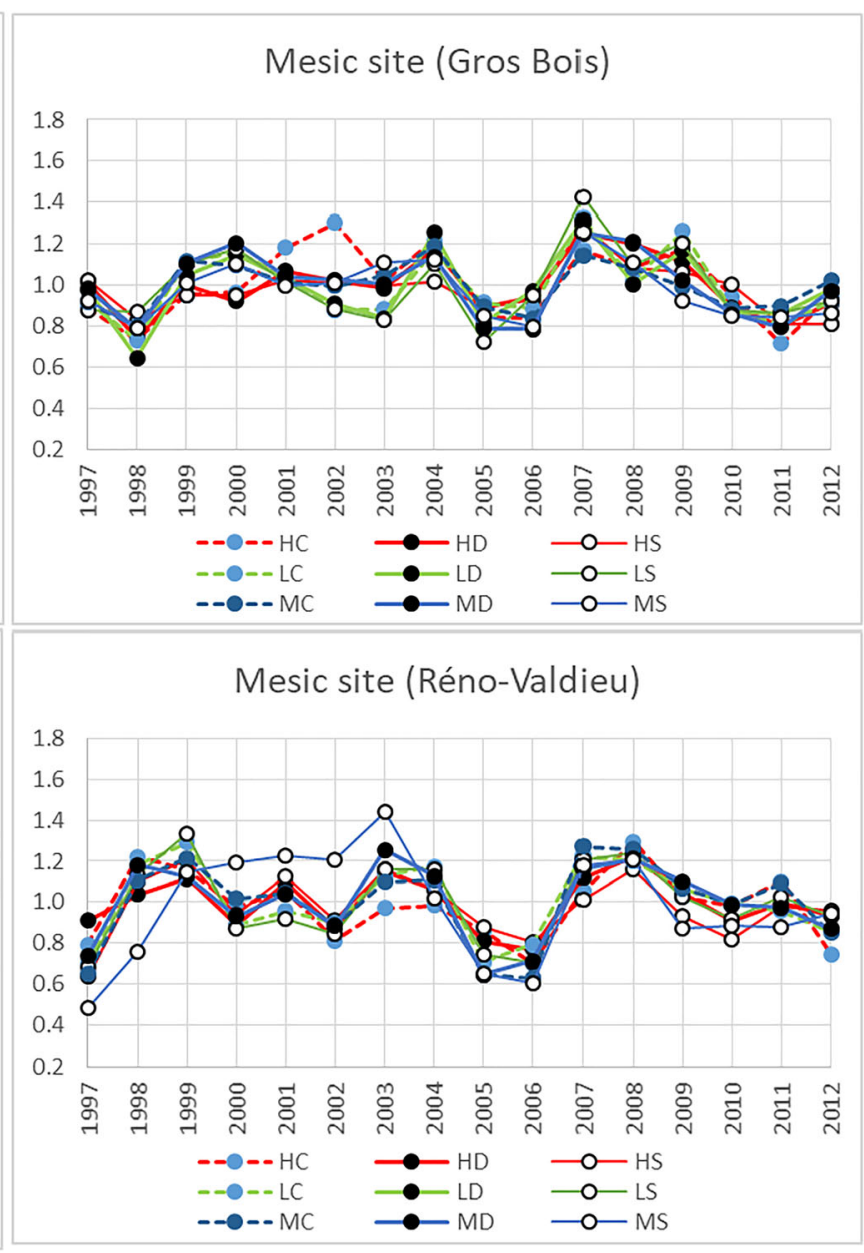




\section{Annex 4}

Mean BAIs according to cambial age (in year) for the 269 oaks sampled. The number of available rings per cambial age varied from 1 to 199 ; mean $97 \pm 62$. The number of different dates per cambial age varied from 1 to 16 (1997-2012). At least 10 different dates were available for the ages from 11 to 35 years and 16 for the ages from 16 to 29 years. Less than 5 different dates before 5 years and after 40 years. The equations used to standardize the BAIs according to the cambial age are presented
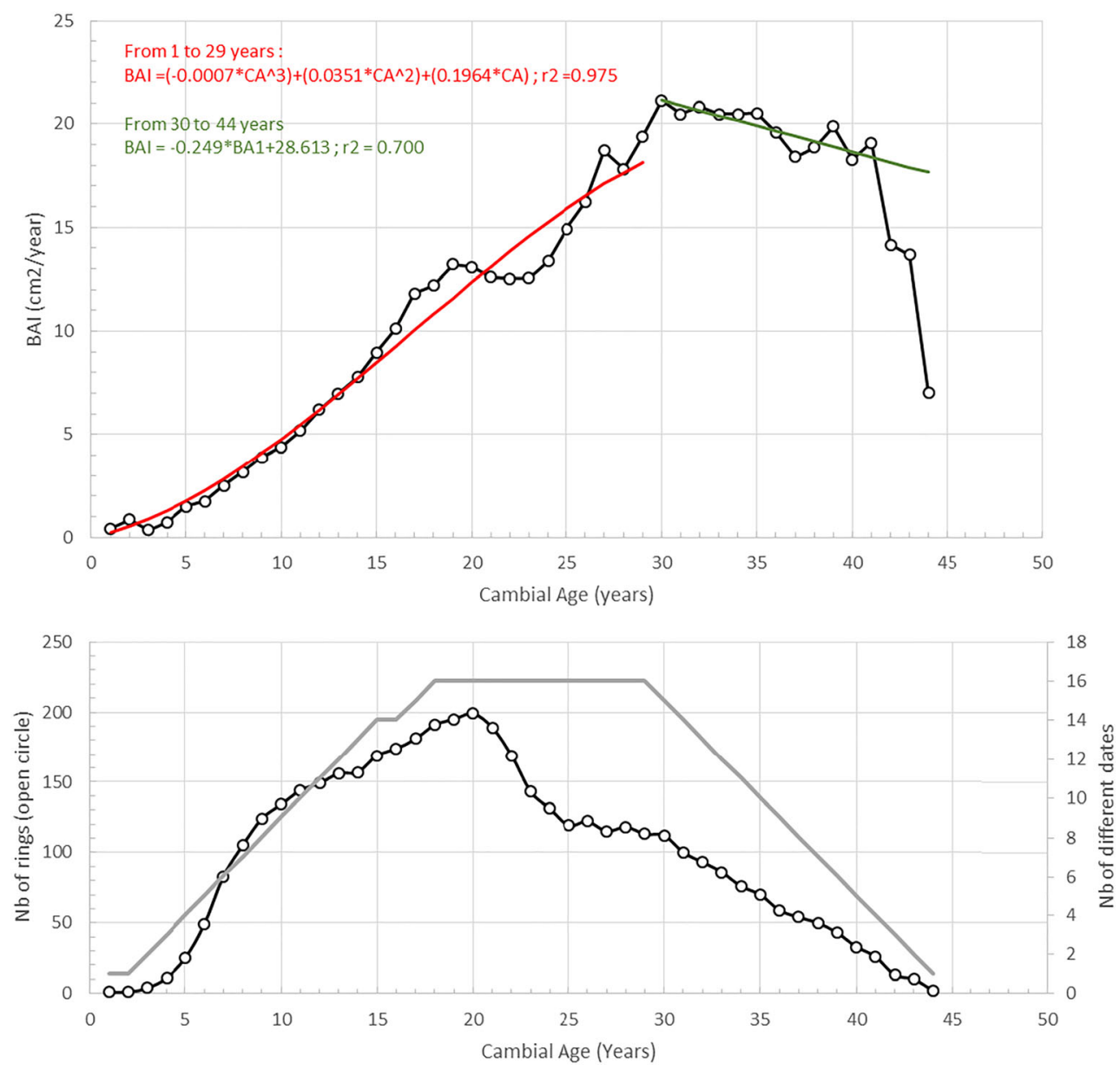


\section{Annex 5}

Structuring of the 33 chronologies (HBc * RDIc * SSc). The analyses have been performed on the tree-ring characteristics ( 7 variables) and the climate conditions (2 variables) calculated from the common period 1997-2012. A Clustering evaluation according to the increase of the $\%$ of the explained inertia by the groups; $\mathbf{B}$ hierarchal cluster analysis according to the Ward D2 method. The percentage of explained variance by clustering is $97.1 \%$ (4 groups); C \% of explained variance of each dimension of the PCA. The first two axes explained $65.2 \%$ of the variance. D Scatter plot of principal component analysis (PCA, dim 1 and dim 2) performed on the matrix (33 chronologies $* 9$ variables) (here variables). Tjan, January temperature
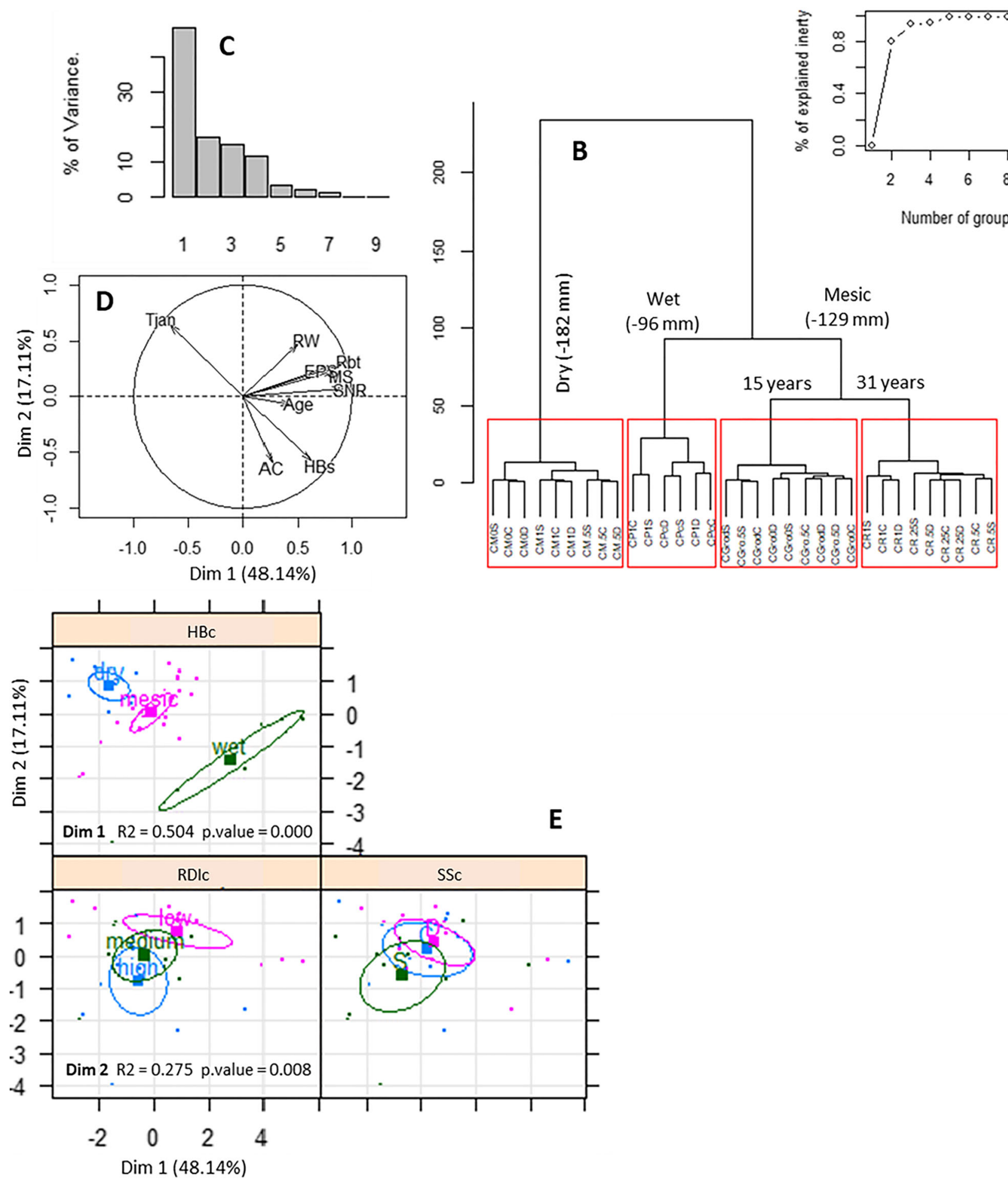

INRAC $\underline{\text { Springer }}$ 
$\left({ }^{\circ} \mathrm{C}\right)$; age in years in 2012 ; HBs, summer water balance $(\mathrm{mm})$; MS, mean sensitivity; EPS, expressed population signal; SNR, signal to noise ration; rbt, coefficient correlation between trees; AC, first-order correlation (see text and Table 2 for details). $\mathbf{E}$ Scatter plot of principal component analysis (PCA, dim 1 and $\operatorname{dim} 2$ ) performed on the matrix (33 chronologies $* 9$ variables) (here chronologies). The figure shows the $95 \%$ ellipse confidence regions for each qualitative variables: $\mathrm{SSc}(\mathrm{S}, \mathrm{C}, \mathrm{D})$; RIDc (high, medium, low); HBc (dry: HBs, - 180 mm; mesic, - $129 \mathrm{~mm}$; wet, $-96 \mathrm{~mm}$ ). The significant coefficients of correlation with the components are also given for each qualitative variables. See text for details.

\section{Annex 6}

Boxplot for resistance, resilience, and recovery according to SSc (D, C, and S) stratified by HBc (dry, mesic, wet). The open circle corresponds to the mean value of the variable for each modality and the dotted line to the overall mean. Means and $p$ values are presented in Table 4 (Tukey's HSD tests).
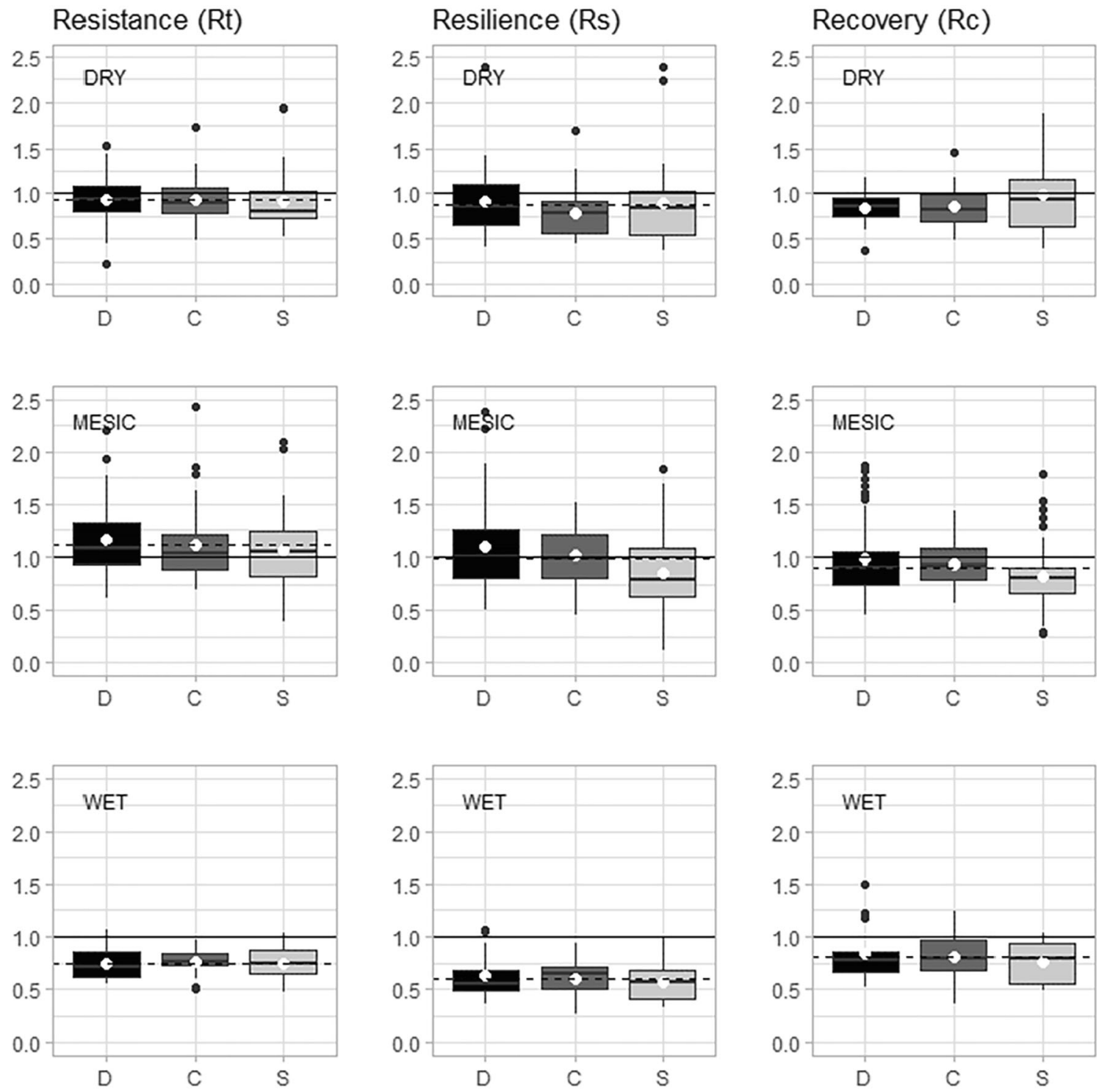


\section{References}

Allen CD, Macalady AK, Chenchouni H, Bachelet D, McDowell N, Vennetier M, Kitzberger T, Rigling A, Breshears DD, Hogg EH, Gonzalez P, Fensham R, Zhang Z, Castro J, Demidova N, Lim JH, Allard G, Running SW, Semerci A, Cobb N (2010) A global overview of drought and heat-induced tree mortality reveals emerging climate change risks for forests. For Ecol Manag 259:660-684

Aussenac G (2000) Interactions between forest stands and microclimate: ecophysiological aspects and consequences for silviculture. Ann For Sci 57:287-301

Aussenac G, Granier A (1988) Effects of thinning on water stress and growth in Douglas-fir. Can J For Res 18:100-105

Barbaroux C, Bréda N, Dufrêne E (2003) Distribution of above-ground and below-ground carbohydrate reserves in adult trees of two contrasting broad-leaved species (Quercus petraea and Fagus sylvatica). New Phytol 157:605-615

Becker M (1989) The role of climate on present and past vitality of silver fir forests in the Vosges mountains of northeastern France. Can J For Res 19:1110-1117

Becker M, Lévy G, Lefèvre Y (1996) Radial growth of mature pedunculate and sessile oaks in response to drainage, fertilization and weedings on acid pseudogley soils. Ann Sci For 53:585-594

Bergès L, Balandier P (2010) Revisiting the use of soil water budget assessment to predict site productivity of sessile oak (Quercus petraea Liebl.) in the perspective of climate change. Eur J Forestry 129:199-208

Bergès L, Nepveu G, Franc A (2008) Effects of ecological factors on radial growth and wood density components of sessile oak (Quercus petraea Liebl.) in Northern France. For Ecol Manag 255: $567-579$

Biondi F, Qeadan F (2008) A theory-driven approach to tree-ring standardization: defining the biological trend from expected basal area increment. Tree Ring Res 64:81-96

Bréda N, Badeau V (2008) Forest tree responses to extreme drought and some biotic events: towards a selection according to hazard tolerance? Compt Rendus Geosci 340:651-662

Bréda N, Granier A, Aussenac G (1995) Effects of thinning on soil and tree water relations, transpiration and growth in an oak forest (Quercus petraea (Matt.) Liebl.). Tree Physiol 15:295-306

Bréda N, Huc R, Granier A, Dreyer E (2006) Temperate forest trees and stands under severe drought: a review of ecophysiological responses, adaptation processes and long-term consequences. Ann For Sci 63:625-644

Bunn AG (2008) A dendrochronology program library in R (dplR). Dendrochronologia 26:115-124

Cailleret M, Jansen S, Robert ER, DeSoto L, Aakala T, Antos JA et al (2016) A synthesis of radial growth patterns preceding tree mortality. Glob Chang Biol. https://doi.org/10.1111/gcb.13535:1-16

Castagneri D, Nola P, Cherubini P, Motta R (2012) Temporal variability of size-growth relationships in a Norway spruce forest: the influences of stand structure, logging, and climate. Can J For Res 42: $550-560$

D'Amato AW, Bradford JB, Fraver S, Palik BJ (2011) Forest management for mitigation and adaptation to climate change: insights from long-term silviculture experiments. For Ecol Manag 262:803-816

D'Amato AW, Bradford JB, Fraver S, Palik BJ (2013) Effects of thinning on drought vulnerability and climate response in north temperate forest ecosystems. Ecol Appl 23:1735-1742

Davi H, Barbaroux C, Francois C, Dufrene E (2009) The fundamental role of reserves and hydraulic constraints in predicting LAI and carbon allocation in forests. Agric For Meteorol 149:349-361

Delpierre N, Vitasse Y, Chuine I, Guillemot J, Bazot S, Rutishauser T, Rathgeber CBK (2016) Temperate and boreal forest tree phenology: from organ-scale processes to terrestrial ecosystem models. Ann For Sci 73:5-25

Friedrichs DA, Trouet V, Buntgen U, Frank DC, Esper J, Neuwirth B, Loffler J (2009) Species-specific climate sensitivity of tree growth in Central-West Germany. Trees Struct Funct 23:729-739

Gea-Izquierdo G, Martin-Benito D, Cherubini P, Canellas I (2009) Climate-growth variability in Quercus ilex L. west Iberian open woodlands of different stand density. Ann For Sci 66:802

Granier A, Bréda N, Biron P, Villette S (1999) A lumped water balance model to evaluate duration and intensity of drought constraints in forest stands. Ecol Model:269-283

Guillemot J, Martin-StPaul NK, Dufrene E, Francois C, Soudani K, Ourcival JM, Delpierre N (2015) The dynamic of the annual carbon allocation to wood in European tree species is consistent with a combined source-sink limitation of growth: implications for modelling. Biogeosciences 12:2773-2790

Guilley E, Herve JC, Huber F, Nepveu G (1999) Modelling variability of within-ring density components in Quercus petraea Liebl. with mixed-effect models and simulating the influence of contrasting silvicultures on wood density. Ann For Sci 56:449-458

Guiot J (1991) The bootstrapped response function. Tree-Ring Bull 51: $39-41$

Gunderson LH (2000) Ecological resilience - in theory and application. Annu Rev Ecol Syst 31:425-439

Gustafson EJ, Sturtevant BR (2013) Modeling forest mortality caused by drought stress: implications for climate change. Ecosystems 16:60 74

Gutschick V.P. and BassiriRad H., 2003. Extreme events as shaping physiology, ecology, and evolution of plants : toward a unified definition and evaluation of their consequences. Tansley Review, New Phytologist 21-42.

Jentsch A, Beierkuhnlein C (2008) Research frontiers in climate change: effects of extreme meteorological events on ecosystems. Compt Rendus Geosci 340:621-628

Kohler M, Sohn J, Nagele G, Bauhus J (2010) Can drought tolerance of Norway spruce (Picea abies (L.) Karst.) be increased through thinning? Eur J For Res 129:1109-1118

Kremer A, Petit RJ (1993) Gene diversity in natural populations of oak species. Ann Sci For 50:186s-202s

Le Goff N, Ottorini JM, Ningre F (2011) Evaluation and comparison of size-density relationships for pure even-aged stands of ash (Fraxinus excelsior L.), beech (Fagus silvatica L.), oak (Quercus petraea Liebl.), and sycamore maple (Acer pseudoplatanus L.). Ann For Sci 68:461-475

Lê S, Husson F (2008) FactoMineR: an R package for Multivariate Analysis. J Stat Softw 25:1-18

Lebourgeois F, Cousseau G, Ducos Y (2004) Climate-tree-growth relationships of Quercus petraea Mill. stand in the Forest of Berce ("Futaie des Clos", Sarthe, France). Ann For Sci 61:361-372

Lebourgeois F, Gomez N, Pinto P, Mérian P (2013) Mixed stands reduce Abies alba tree-ring sensitivity to summer drought in the Vosges mountains, Western Europe. For Ecol Manag 303:61-71

Lebourgeois F, Eberlé P, Mérian P, Seynave I (2014) Social statusmediated tree-ring responses to climate of Abies alba and Fagus sylvatica shift in importance with increasing stand basal area. For Ecol Manag 328:209-2018

Lenth RV (2016) Least-Squares Means: The R Package lsmeans. J Stat Softw 69:1-33

Lévy G, Becker M, Duhamel D (1992) A comparison of the ecology of pedunculate and sessile oaks: radial growth in the centre and northwest of France. For Ecol Manag 55:51-63

Lindner M, Maroschek M, Netherer S, Kremer A, Barbati A, GarciaGonzalo J, Seidl R, Delzon S, Corona P, Kolstrom M, Lexer MJ, Marchetti M (2010) Climate change impacts, adaptive capacity, and 
vulnerability of European forest ecosystems. For Ecol Manag 259: 698-709

Liu Y, Muller RN (1993) Effect of drought and frost on radial growth of overstory and understory stems in a deciduous forest. Am Midl Nat 129:19-25

Lloret F, Keeling EG, Sala A (2011) Components of tree resilience: effects of successive low-growth episodes in old ponderosa pine forests. Oikos 120:1909-1920

Lloret F, Escudero A, Iriondo JM, Martinez-Vilalta J, Valladares F (2012) Extreme climatic events and vegetation: the role of stabilizing processes. Glob Chang Biol 18:797-805

Magruder M, Chhin S, Palik B, Bradford JB (2013) Thinning increases climatic resilience of red pine. Can J For Res 43:878-889

Martin-Benito D, Cherubini P, del Rio M, Canellas I (2008) Growth response to climate and drought in Pinus nigra Arn. trees of different crown classes. Trees Struct Funct 22:363-373

Martin-Benito D, Del Rio M, Heinrich I, Helle G, Canellas I (2010) Response of climate-growth relationships and water use efficiency to thinning in a Pinus nigra afforestation. For Ecol Manag 259:967975

Martin-Benito D, Kint V, del Rio M, Muys B, Canellas I (2011) Growth responses of West-Mediterranean Pinus nigra to climate change are modulated by competition and productivity: Past trends and future perspectives. For Ecol Manag 262:1030-1040

Martinez-Vilalta J, Lopez BC, Loepfe L, Lloret F (2012) Stand- and treelevel determinants of the drought response of Scots pine radial growth. Oecologia 168:877-888

Mérian P (2012) POINTER et DENDRO : deux applications sous R pour l'analyse de la réponse des arbres au climat par approche dendroécologique. Revue Forestière Française 64:789-798

Mérian P, Lebourgeois F (2011a) Consequences of decreasing the number of cored trees per plot on chronology statistics and climategrowth relationships: a multispecies analysis in a temperate climate. Can J For Res 41:2413-2422

Mérian P, Lebourgeois F (2011b) Size-mediated climate-growth relationships in temperate forests: a multi-species analysis. For Ecol Manag 261:1382-1391

Mérian P, Bontemps JD, Bergès L, Lebourgeois F (2011) Spatial variation and temporal instability in climate-growth relationships of sessile oak (Quercus petraea [Matt.] Liebl.) under temperate conditions. Plant Ecol 212:1855-1871

Merlin M, Pérot T, Perret S, Korboulewsky N, Vallet P (2015) Effects of stand composition and tree size on resistance and resilience to drought in sessile oak and Scots pine. For Ecol Manag 339:22-33

Meyer FD, Bräker OU (2001) Climate response in dominant and suppressed spruce trees, Picea abies (L.) Karst., on a subalpine and lower montane site in Switzerland. Ecoscience 8:105-114

Michelot A, Simard S, Rathgeber C, Dufrene E, Damesin C (2012) Comparing the intra-annual wood formation of three European species (Fagus sylvatica, Quercus petraea and Pinus sylvestris) as related to leaf phenology and non-structural carbohydrate dynamics. Tree Physiol 32:1033-1045

Misson L, Nicault A, Guiot J (2003a) Effects of different thinning intensities on drought response in Norway spruce (Picea abies (L.) Karst.). For Ecol Manag 183:47-60

Misson L, Vincke C, Devillez F (2003b) Frequency responses of radial growth series after different thinning intensities in Norway spruce (Picea abies (L.) Karst.) stands. For Ecol Manag 177:51-63

Neumann M, Mues V, Moreno A, Hasenauer H, Seidl R (2017) Climate variability drives recent tree mortality in Europe. Glob Chang Biol 23:4788-4797

Novak J, Slodičák M, Kacálek D, Dušek D (2010) The effect of different stand density on diameter growth response in Scots pine stands in relation to climate situations. J For Sci 56:461-473

Olivar J, Bogino S, Spiecker H, Bravo F (2012) Climate impact on growth dynamic and intra-annual density fluctuations in Aleppo pine (Pinus halepensis) trees of different crown classes. Dendrochronologia 30:35-47

Orwig DA, Abrams MD (1997) Variation in radial growth responses to drought among species, site, and canopy strata. Trees Struct Funct 11:474-484

Pérez-de-Lis G, Garcia-Gonzalez I, Rozas V, Arevalo JR (2011) Effects of thinning intensity on radial growth patterns and temperature sensitivity in Pinus canariensis afforestations on Tenerife Island. Spain Ann For Sci 68:1093-1104

Perez-de-Lis G, Olano JM, Rozas V, Rossi S, Vazquez-Ruiz RA, GarciaGonzalez I (2017) Environmental conditions and vascular cambium regulate carbon allocation to xylem growth in deciduous oaks. Funct Ecol 31:592-603

Pichler P, Oberhuber W (2007) Radial growth response of coniferous forest trees in an inner Alpine environment to heat-wave in 2003. For Ecol Manag 242:688-699

Pretzsch H, Schutze G, Uhl E (2013) Resistance of European tree species to drought stress in mixed versus pure forests: evidence of stress release by inter-specific facilitation. Plant Biol 15:483-495

Pretzsch H, del Río M, Biber P, Arcangeli C, Bielak K, Brang P, Dudzinska M, Forrester DI, Klädtke J, Kohnle U, Ledermann T, Matthews R, Nagel J, Nagel R, Nilsson U, Ningre F, Nord-Larsen T, Wernsdörfer H, Sycheva E (2019) Maintenance of long-term experiments for unique insights into forest growth dynamics and trends: review and perspectives. Eur J For Res 138:165-185

Rebetez M, Mayer H, Dupont O, Schindler D, Gartner K, Kropp JP, Menzel A (2006) Heat and drought 2003 in Europe: a climate synthesis. Ann For Sci 63:569-577

Reineke LH (1933) Perfecting a Stand-density Index for Even-aged Forests. J Agric Res 46:627-638

Ruiz-Benito P, Ratcliffe S, Zavala MA, Martinez-Vilalta J, Vila-Cabrera A, Lloret F, Madrigal-Gonzalez J, Wirth C, Greenwood S, Kandler G, Lehtonen A, Kattge J, Dahlgren J, Jump AS (2017) Climate- and successional-related changes in functional composition of European forests are strongly driven by tree mortality. Glob Chang Biol 23: 4162-4176

Saenz-Romero C, Lamy JB, Ducousso A, Musch B, Ehrenmann F, Delzon S, Cavers S, Chalupka W, Dagdas S, Hansen JK, Lee SJ, Liesebach M, Rau HM, Psomas A, Schneck V, Steiner W, Zimmermann NE, Kremer A (2017) Adaptive and plastic responses of Quercus petraea populations to climate across Europe. Glob Chang Biol 23:2831-2847

Sánchez-Salgueroa R, Carlos Linares JC, Camarero J, MadrigalGonzález J, Heviae A, Sánchez-Miranda A, Ballesteros-Cánovas JA, Alfaro-Sánchez R, García-Cervigón AI, Bigler C, Rigling A (2015) Disentangling the effects of competition and climate on individual tree growth: a retrospective and dynamic approach in Scots pine. For Ecol Manag 358:12-25

Schar C, Vidale PL, Luthi D, Frei C, Haberli C, Liniger MA, Appenzeller $\mathrm{C}$ (2004) The role of increasing temperature variability in European summer heatwaves. Nature 427:332-336

Schmitt A. 2017. Effect of forest management on sessile oak (Quercus petrea) response to climate: a dendroecological approach. Master FAGE Biology and Ecology for Forest, Agriculture and Environment MSc Major Forests and their Environment (FEN), 38 p.

Seynave I, Bailly A, Balandier P, Bontemps JD, Cailly P, Cordonnier T, Deleuze C, Dhote JF, Ginisty C, Lebourgeois F, Merzeau D, Paillassa E, Perret S, Richter C, Meredieu C (2018) GIS Coop: networks of silvicultural trials for supporting forest management under changing environment. Ann For Sci 75:1-20

Sohn JA, Kohler M, Gessler A, Bauhus J (2012) Interactions of thinning and stem height on the drought response of radial stem growth and isotopic composition of Norway spruce (Picea abies). Tree Physiol 32:1199-1213 
Sohn JA, Gebhardt T, Ammer C, Bauhus J, Haberle KH, Matyssek R, Grams TEE (2013) Mitigation of drought by thinning: short-term and long-term effects on growth and physiological performance of Norway spruce (Picea abies). For Ecol Manag 308:188-197

Sohn JA, Saha S, Bauhus J (2016) Potential of forest thinning to mitigate drought stress: A meta-analysis. For Ecol Manag 380:261-273

Sterl A, Severijns C, Dijkstra H, Hazeleger W, Jan van Oldenborgh G, van den Broeke M, Burgers G, van den Hurk B, Jan van Leeuwen P, van Velthoven $P$ (2008) When can we expect extremely high surface temperatures? Geophys Res Lett 35:L14703

Thornthwaite C.W. and Mather J.R., 1955. The water balance. Drexel Institute of Climatology Laboratory, Climatology publication 8: 1-104.

Timbal J, Aussenac G (1996) An overview of ecology and silviculture of indigenous oaks in France. Ann Sci For 53:649-661

Toth B, Weynants M, Nemes A, Mako A, Bilas G, Toth G (2015) New generation of hydraulic pedotransfer functions for Europe. Eur J Soil Sci 66:226-238

Trouvé R, Bontemps JD, Collet C, Seynave I, Lebourgeois F (2014) Growth partitioning in forest stands is affected by stand density and summer drought in sessile oak and Douglas-fir. For Ecol Manag 334:358-368

Trouvé R, Bontemps JD, Seynave I, Collet C, Lebourgeois F (2015) Stand density, tree social status and water stress influence allocation in height and diameter growth of Quercus petraea (Liebl.). Tree Physiol 35:1035-1046

Trouvé R, Bontemps JD, Collet C, Seynave I, Lebourgeois F (2016) Radial growth resilience of sessile oak after drought is affected by site water status, stand density, and social status. Trees Struct Funct 31:517-529. https://doi.org/10.1007/s00468-016-1479-1

Trouvé R, Bontemps JD, Seynave I, Collet C, Lebourgeois F (2019) When do dendrometric rules fail? Insights from 20 years of experimental thinnings on sessile oak in the GIS Coop network. For Ecol Manag 433:276-286

Turc L (1961) Evaluation des besoins en eau d'irrigation. Evapotranspiration potentielle. Annales Agronomiques 12: 13-49

Tyree MT, Cochard H (1996) Summer and winter embolism in oak: impact on water relations. Ann Sci For 53:173-180

Van Den Brakel JA, Visser H (1996) The influence of environmental conditions on tree-ring series of Norway spruce for different canopy and vitality classes. For Sci 42:206-219

Vidal JP, Martin E, Franchisteguy L, Habets F, Soubeyroux JM, Blanchard M, Baillon M (2010) Multilevel and multiscale drought reanalysis over France with the Safran-Isba-Modcou hydrometeorological suite. Hydrol Earth Syst Sci 14:459-478

Vose JM, Swank WT (1994) Effects of long-term drought on the hydrology and growth of a white-pine plantation in the southern Appalachians. For Ecol Manag 64:25-39

Zang C, Biondi F (2013) Dendroclimatic calibration in R: the bootRes package for response and correlation function analysis. Dendrochronologia 31:68-74

Zang C, Pretzsch H, Rothe A (2012) Size-dependent responses to summer drought in Scots pine, Norway spruce and common oak. Trees Struct Funct 26:557-569

Zhang SY, Owoundi RY, Nepveu G, Mothe F, Dhôte JF (1993) Modelling wood density in European oak (Quercus petraea and Quercus robur) and simulating the silvicultural influence. Can J For Res 23:2587-2593

Publisher's note Springer Nature remains neutral with regard to jurisdictional claims in published maps and institutional affiliations. 